This item was submitted to Loughborough's Research Repository by the author.

Items in Figshare are protected by copyright, with all rights reserved, unless otherwise indicated.

\title{
Effect of scarfing on rectangular nozzle supersonic jet plume flow characteristics
}

\section{PLEASE CITE THE PUBLISHED VERSION}

https://doi.org/10.2514/1.J055526

\section{PUBLISHER}

(C) American Institute of Aeronautics and Astronautics

\section{VERSION}

AM (Accepted Manuscript)

\section{PUBLISHER STATEMENT}

This work is made available according to the conditions of the Creative Commons Attribution-NonCommercialNoDerivatives 4.0 International (CC BY-NC-ND 4.0) licence. Full details of this licence are available at: https://creativecommons.org/licenses/by-nc-nd/4.0/

\section{LICENCE}

CC BY-NC-ND 4.0

\section{REPOSITORY RECORD}

Behrouzi, Parviz, Jim McGuirk, and C. Avenell. 2019. "Effect of Scarfing on Rectangular Nozzle Supersonic Jet Plume Flow Characteristics". figshare. https://hdl.handle.net/2134/36708. 


\title{
Effect of Scarfing on Rectangular Nozzle Supersonic Jet Plume Flow Characteristics
}

\author{
P. Behrouzi ${ }^{1}$, J. J. McGuirk ${ }^{1}$, and C. Avenell ${ }^{2}$ \\ ${ }^{1}$ Department of Aeronautical and Automotive Engineering, Loughborough University, \\ Loughborough LE11 3TU, UK \\ ${ }^{2}$ Rolls-Royce plc, WH-64 Whittle House, PO Box 3, \\ Bristol BS34 7QE, UK
}

An experimental and CFD study is reported of supersonic jets issuing from a high aspect ratio rectangular convergent-divergent nozzle with and without a scarfed exit. Schlieren visualisation and LDA measurements captured near-field aerodynamic development of an unheated jet at over-expanded, design, and underexpanded conditions. RANS CFD predictions using an eddy viscosity closure (Spalart-Almaras model) for clean and scarfed geometries were compared with measurements to examine the ability to capture nozzle scarfing effects. The measured plume shape for a scarfed nozzle was strongly affected at over-expanded conditions - a distorted 4-lobe shape was observed - whereas a rectangular shape was retained for underexpanded flow although plume bifurcation occurred. Development of the plume shape and the mixing rate were a consequence of the strong vortices that occur with rectangular nozzles, with extra vortices introduced by scarfing. The nozzle exit static pressure changed dramatically when scarfing was added, influencing plume secondary flows and near-field development. The main features of scarfed jet development were predicted qualitatively correctly - the 4-lobe over-expanded shape was reproduced, but the strength of pressure-driven secondary velocities was over-predicted. The experimental data provided represent a challenging validation test case for CFD studies of 3D supersonic jet plumes with scarfed interaction effects. 


\section{Nomenclature}

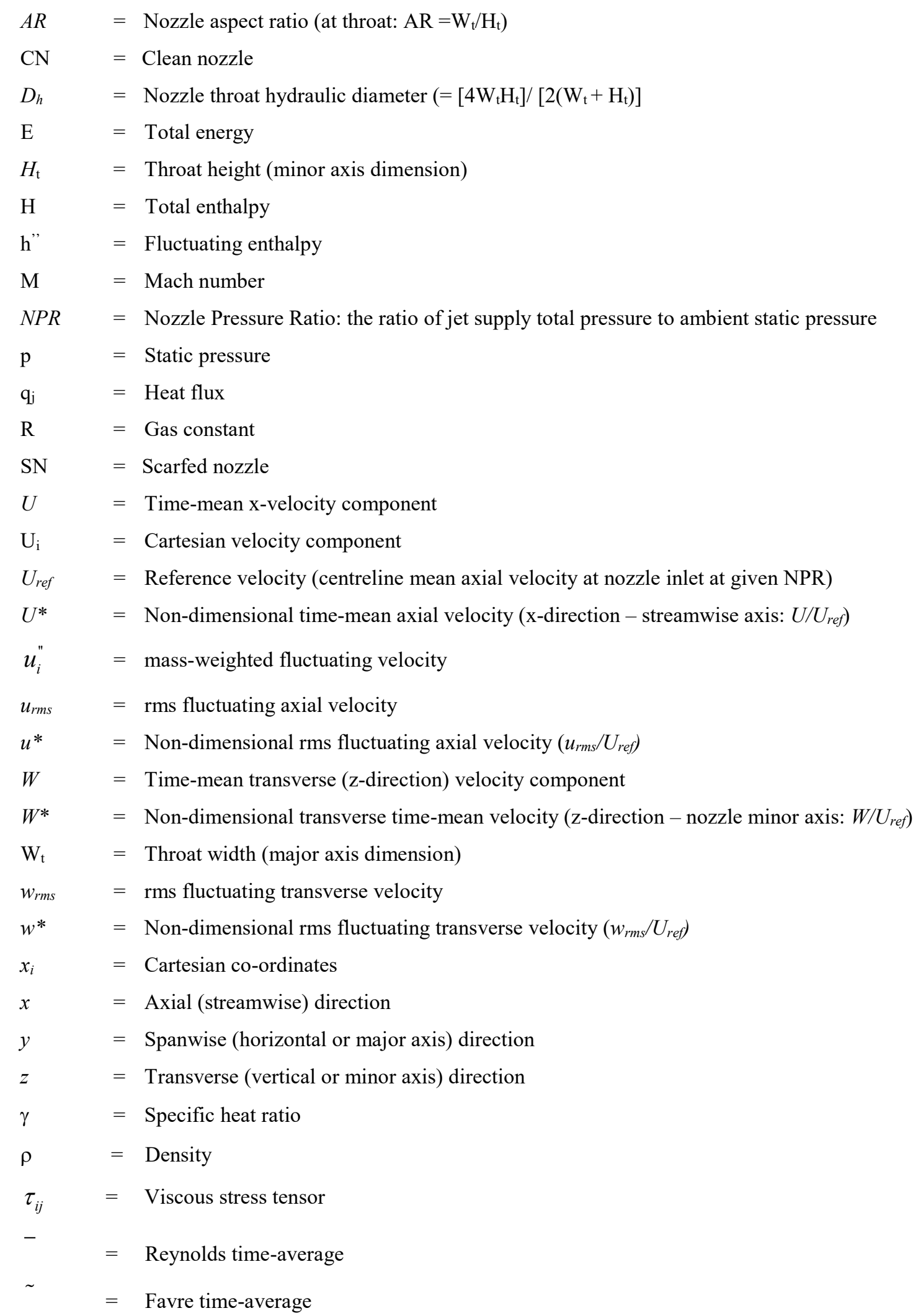




\section{I.Introduction}

Improved propulsion exhaust nozzle design is of increasing importance, with engineering applications such as low noise for civil aircraft and low observability for military air vehicles. In the 1970's non-axisymmetric nozzles were identified as offering advantages including lower cruise/manoeuvring drag and enhanced plume/ambient mixing (Hiley et al. ${ }^{1}$ ). Shyne ${ }^{2}$ highlighted the aerodynamic challenges of novel exhaust nozzle technologies and Gamble et al. ${ }^{3}$ have reviewed current approaches to nozzle selection/design. For military aircraft survivability demands low-observable properties. Reduced radar cross-section (RCS) requires modification to intake/exhaust geometries, increased wing sweep, and surface shaping. Low infra-red signature (IRS) requires cooling of hot surfaces and rapid jet plume temperature reduction. The link between enhanced plume mixing and nozzle shape has been well documented - early NASA studies (Lamb et al. ${ }^{4}$ ) described the benefits of rectangular nozzles for both RCS and IRS and Mahulikar et al. ${ }^{5}$ provided a review of nozzle geometry options for IRS suppression. High aspect ratio rectangular nozzles have also achieved reduced noise for civil aircraft applications (Bridges ${ }^{6}, \mathrm{Zaman}^{7}$ ). Nozzle trailing edge cut-outs (notches or slots) further enhance plume mixing by introduction of streamwise vorticity into the jet near-field. Experimental measurements demonstrating IRS reduction were provided by Dix et al. ${ }^{8}$ for a convergent round nozzle - the hottest part of the plume was shortened by $\sim 33 \%$ with little thrust loss. This technology (chevrons or serrations) has, however, been used more for jet noise than IRS reduction.

Integration of exhaust system and aircraft afterbody combined with low RCS shaping leads to change of the nozzle exit plane angle with respect to the plume flow direction. In the F117 for example $\left(\right.$ Brown $\left.^{9}\right)$ a 'letter box' nozzle with exit plane parallel to the wing trailing edge sweep created an angled but still basically rectangular geometry. A nozzle exit plane that is non-orthogonal to the nozzle axis is typically described as 'scarfing'. Particularly at off-design conditions this can contribute significantly to jet near-field mixing and cross-sectional shape change. The focus of the work reported here is placed on this aspect i.e. a study of nozzle scarfing effects on near-field plume characteristics for high aspect ratio rectangular nozzles. Operating conditions covering Nozzle Pressure Ratios (NPR = jet total pressure/ambient static pressure) at over- , fully- and under-expanded conditions are considered. Whilst hot jets occur in practice (Nozzle Temperature Ratio NTR $=$ jet total temperature/ambient static temperature greater than 1) the present work only considers unheated jets. A detailed study of round convergent nozzles at high subsonic NPR by Bridges and Wernet $^{10}$ has shown that, when scaled appropriately, their near-field mean velocity and turbulence measurements for hot jets collapsed onto the NTR $=1$ data. Jet heating reduces 
potential core length and near-field jet spreading rate, but if these are taken into account via axial/radial re-scaling, little influence of hot jet conditions could be seen. It is likely that similar behaviour may be expected for rectangular jets, and thus the present work concentrates on gathering aerodynamic data at unheated conditions, leaving potential core/spread rate effects of jet heating for rectangular jets to be established in a future study.

The complex fluid mechanics of rectangular jets has been studied for 40 years. Behrouzi and McGuirk ${ }^{11}$ have summarised published literature on the near-field aerodynamics at both subsonic and supersonic conditions. Two (connected) features appear that are not present in axisymmetric jets -'saddle-shaped' velocity profiles and 'axisswitching' (the exchange of orientation of major/minor axes of the jet from the nozzle exit configuration). These features are introduced by the secondary flows (in the plane of the jet cross-section) generated in 3D jets. Hussain and Husain ${ }^{12}$ were the first to explain how near-field entrainment and the developing jet cross-sectional shape for non-axisymmetric jets are controlled by the azimuthal turbulent structures created at the nozzle lip. These roll up into vortex rings initially aligned with the nozzle exit geometry. Variations in vortex strength and radius of curvature around the ring then lead to ring deformation due to Biot-Savart law induced velocity around the ring. Segments at either end of the major axis have higher induced velocity than segments at minor axis ends, causing fluid at the major axis ends to convect faster downstream and radially inwards relative to fluid at the minor axis ends. This outof-plane distortion is accompanied by rapid entrainment/growth in the minor axis direction, whilst the major axis jet edge hardly grows or even moves inwards. If this mechanism is vigorous enough axis-switching occurs. The strength of the process is controlled by the (Reynolds number dependent) boundary layer thickness at nozzle exit. Thus, it does not always occur and is observed most often at subsonic Mach numbers and at lower Reynolds numbers. Putnam and Mercer ${ }^{13}$ and Von Glahn ${ }^{14}$, however, have noted the same flow characteristics can also appear at high subsonic and supersonic Mach numbers, and both saddle-shaped profiles and axis-switching have been observed in shock-containing supersonic jet flow from rectangular nozzles by Veltin and McLaughlin ${ }^{15}$ and Behrouzi and McGuirk ${ }^{11}$.

Most of the above measurements were focussed on revealing the flow physics of rectangular jets and were conducted using pneumatic probe instrumentation. For CFD validation purposes turbulence measurements are also needed. Laser-based instrumentation was applied to a rectangular jet plume by Behrouzi and McGuirk ${ }^{11}$ for a convergent rectangular nozzle (aspect ratio $=7.35$ ); detailed mapping of mean velocity and turbulence statistics in major and minor axis planes was provided for NPRs corresponding to choked, mild and strong under-expansion. 
Whilst this study is a good example of the level of detail important for CFD validation, it is not entirely satisfactory for the present purpose - it focussed principally on the effect of addition of an aft-deck on near-field plume characteristics and the use of a convergent only nozzle is not representative of military applications where convergent-divergent nozzles are used and both over- and under-expansion states can occur.

As well as vortex ring deformation, for shock-containing jets a further phenomenon must be considered - the possible occurrence and influence of screech. Screech is tonal noise produced as a result of an acoustically-driven self-excited feedback loop. Shear layer disturbances (instabilities or large scale turbulent eddies) grow as they convect downstream of the nozzle lip and interact with shock-cells creating sound waves. These propagate upstream in the subsonic regions at the edge and outside the jet and are reflected/scattered on reaching the nozzle lip to create new shear layer disturbances to continue the cycle, with the appearance of 'screech tones' in the radiated noise. Observations of screech in imperfectly expanded rectangular jets have been reported by Behrouzi and McGuirk ${ }^{11}$, Zaman ${ }^{16}$, Krothapalli et al. ${ }^{17}$, Alkislar et al. ${ }^{18}$ and Valentich et al. ${ }^{19}$. In addition, Raman ${ }^{20,}{ }^{21}$ has provided a comprehensive review of work on screech in rectangular jets from convergent-divergent nozzles, including the effect of non-uniform nozzle exit geometry. Analysis of the available experimental data clearly showed that screech characteristics (mode, amplitude) were strongly dependent on the shock-cell structure. For screech to occur required: (i) the instability to grow to a sufficient size and strength, and (ii) the pressure change across the shock cells to be sufficiently large. Thus, for a straight rectangular nozzle exit the source of the screech tone is often considered to be located at the $3^{\text {rd }}$ or $4^{\text {th }}$ shock-cell. Whilst the predominant mode for a straight nozzle exit geometry is a transverse anti-symmetric (flapping orthogonal to the nozzle major axis) and spanwise symmetric motion, Raman ${ }^{20}$ showed that a spanwise anti-symmetric mode could also be found when the shock-cell structure was weakened near the nozzle design NPR. Of course for a complex geometry nozzle trailing edge, strong spanwise variations in shock cell structure are inevitable, and hence both spanwise symmetric and anti-symmetric modes are always observed. $\operatorname{Raman}^{20}$ studied two types of non-uniform nozzle exit: a spanwise oblique edge (single-beveled design) and a double-beveled arrowhead shaped edge (referred to here as 'scarfed'). It was observed that with the scarfed design the onset of screech was shifted to a higher value of NPR, screech amplitude was typically weaker and over a narrower range of NPR compared to straight and single-beveled shapes, and both spanwise symmetric and antisymmetric modes occurred. 
The above studies indicated that, if the intensity of the screech tone is high, interaction with the mean flowfield can occur and the streamwise vortex structures and consequently the possibility of axis-switching can be strengthened. However, it has also been noted that weak screech does not interact strongly with the mean flowfield, merely superimposing an unsteady periodic component onto the turbulent fluctuations within the potential core region. For example, Krothapalli et al. ${ }^{17}$ observed no change of jet spreading angle from its non-screech value for NPRs of 2.4 and 5.4 in spite of clear evidence of screech, whereas at the peak screech condition of NPR $=3.8$ a $60 \%$ increase in spreading was observed. Similarly, Behrouzi and McGuirk ${ }^{11}$ noted no mean flow effects of screech at a mild under-expanded NPR but significant effects for strong under-expansion when screech intensity increased. In Alkislar et al's ${ }^{18}$ measurements high amplitude screech only occurred at specific NPR values in both over- and under-expanded jets, and just $+/-15 \%$ deviation from the peak noise NPR lead to a sound intensity reduction of an order of magnitude. Finally, it must be borne in mind that, whilst the screech phenomenon is of significant interest fluid mechanically, the structurally damaging effects of high intensity screech means that in practical applications design efforts are undertaken to avoid the off-design NPR operating conditions that involve strong screech tones (heated jets also are less prone to screech). Thus, when considering test cases suitable for assessing the capability of CFD for design, it is necessary to avoid high screech intensity conditions and this approach has been followed in the present work.

The presence of nozzle scarfing undoubtedly introduces extra effects. Lilley ${ }^{22}$ has described design methods for scarfed nozzles in missiles where flush-mounted exit through the side rather than the rear of the vehicle was the first occurrence of scarfing. Unfortunately, only internal expansion processes with no application to external plume development were considered. Some research has been undertaken to understand what effect scarfing has on vortex ring dynamics. New ${ }^{23}$ and New and Tsovolous ${ }^{24}$ performed PIV measurements on elliptic nozzles with several scarf angles. For low angles of incline the vortex ring remained aligned with the original nozzle exit, but for larger angles the incline increased downstream. Strong axis-switching occurred in the non-scarfed elliptic nozzle, but both $30^{\circ}$ and $60^{\circ}$ inclined nozzles produced significant suppression of the axis-switching behaviour. It was argued these observations were consistent with the vortex ring self-induction process, but caution must be used if these conclusions are to be considered generally valid, since all measurements were at low $\operatorname{Re}(\sim 2500)$ and at incompressible (water flow) conditions. 
Rather few studies have been published on rectangular nozzle scarfing at high Mach numbers, with little detailed measurements available. Samimy et al. ${ }^{25}$ and Kim and Samimy ${ }^{25}$ carried out experiments on rectangular nozzles with different trailing edge angles to examine enhanced mixing and noise reduction benefits, with some attention given to plume development, although via flow visualisation only. The baseline nozzle geometry was convergent-divergent with an aspect ratio 3 exit shape operated at moderately over-expanded $(M=1.75)$, fully-expanded $(M=2.0)$ and moderately under-expanded $(M=2.5)$ conditions. Scarfed and sawtooth trailing edge shapes were explored at sweep angles of $35^{\circ}, 45^{\circ}$, and $55^{\circ}$. Scarfing made little difference to jet cross-section evolution for the ideally-expanded case, with no axis switching and gradual development into an axisymmetric shape. In contrast, pairs of streamwise vortices were generated at the under-expanded condition, the spanwise surface pressure gradient introduced by scarfing being identified as the source. In the over-expanded flow regime an internal nozzle flow separation prevented firm conclusion being drawn. Once again caution is warranted when generalising these observations. Finally, as noted above, Raman ${ }^{20,21}$ has provided a study of a 4.75:1 aspect ratio scarfed rectangular nozzle at overexpanded, design, and under-expanded conditions. In order to understand the shock-cell structures produced, a small pneumatic probe was employed to document the static pressure field on axial planes through the major and minor axes of the jet plume. However, no quantitative velocity or turbulence measurements were carried out and the detailed effects of scarfing on the supersonic cores of high speed rectangular jets remains to be established.

On the basis of the above review it is clear that it would be valuable to capture detailed flow field measurements in a scarfed rectangular convergent-divergent high aspect ratio nozzle jet plume for a range of representative NPR operating conditions. The main objective of the present work was therefore to produce a measurement database of velocity and turbulence properties for both a plain and a scarfed exit plane. In addition, since no CFD studies to predict scarfing effects have been carried out, a second objective was to use the data taken as a CFD validation test case to establish the ability of a Reynolds Averaged Navier-Stokes (RANS) eddy viscosity turbulence model to predict scarfed rectangular supersonic jets.

\section{II.Experimental Facility and Instrumentation}

\section{A. High Pressure Nozzle Test Facility (HPNTF)}

Measurements were carried out in the High Pressure Nozzle Test Facility (HPNTF) at Loughborough University. Behrouzi and McGuirk ${ }^{11}$ provide a full description of the facility and instrumentation and only brief details are provided here. A maximum flow rate of $1 \mathrm{~kg} / \mathrm{s}$ of high pressure air at a maximum pressure of 14 Bar (gauge) and a 
dew point of $-40 \mathrm{C}$ is available, with $110 \mathrm{~m}^{3}$ of air storage provided for blow-down testing at higher flow rates; automatic control valves hold mass flow constant to $+/-1 \%$.

\section{B. Rectangular Nozzle Design}

Two convergent-divergent nozzles - clean and scarfed - were designed. The clean design had inlet, throat, and nozzle exit heights of $25.0 \mathrm{~mm}, 13.1 \mathrm{~mm}$, and $15.75 \mathrm{~mm}$, with width remaining constant at $91.6 \mathrm{~mm}$. The nozzle exit lip thickness was chosen to be as thin as possible adopting standard manufacturing practice. This aspect of nozzle geometry will influence the particular screech characteristics of the nozzle, and thin nozzle lips minimises (but does not eliminate) the peak screech amplitude; a $1 \mathrm{~mm}$ thickness was deemed acceptable. The throat hydraulic diameter $\left(D_{\mathrm{h}}=22.92 \mathrm{~mm}\right)$ was chosen as the reference length for co-ordinate non-dimensionalisation. The convergence/divergence angles and axial lengths were $6 \% 56.6 \mathrm{~mm}$ and $1.36^{\circ} / 55.78 \mathrm{~mm}$. Ideal expansion was calculated to be at NPR $=4$ (fully-expanded Mach number $=1.56$ ). This was an inviscid approximation ignoring losses and inlet boundary layer effects. The actual design NPR was identified using flow visualisation .Note also that the throat corner had a rounded shape with a radius of order $10 \mathrm{~mm}$; thus flow turning created weak oblique pressure

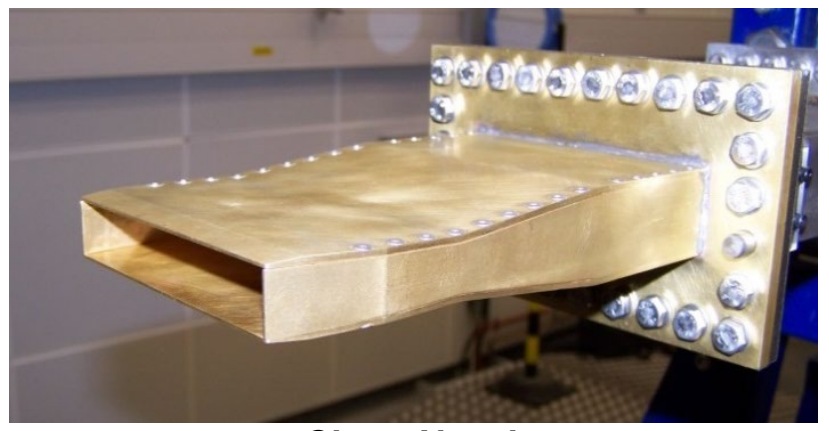

Clean Nozzle

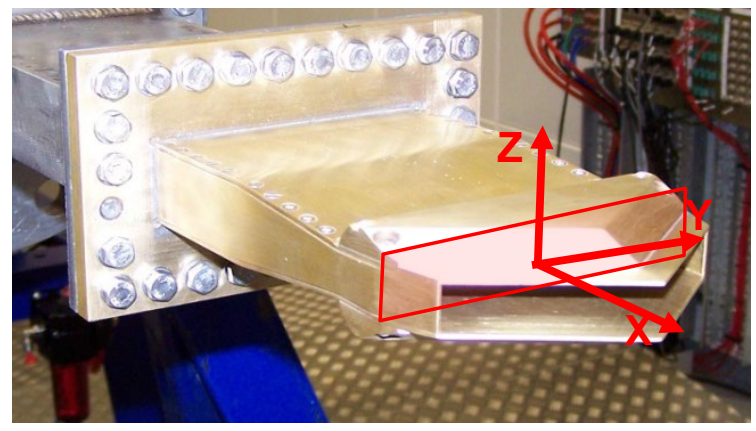

Scarfed Nozzle

Fig. 1 Views of (left) clean nozzle (CN) and (right) scarfed nozzle (SN)

waves occurred inside the nozzle even at the design NPR and these could be seen in the jet plume, see Fig.3 below.

The scarf angle for the second nozzle was set at $35^{\circ}$, which is at the lower end of the range used in previous scarfed nozzle measurements. Divergence length measured on the nozzle centreline was increased to $71.55 \mathrm{~mm}$. The divergent section had an initial un-scarfed length and was designed so that the nozzle exit area projected in the axial direction was equal to the clean nozzle exit area; the scarfed nozzle exit then intersected the nozzle side wall a short distance downstream of the throat. Thus in a 1D design context the area ratios of both nozzles was the same. Fig. 1 presents photos of clean $(\mathrm{CN})$ and scarfed $(\mathrm{SN})$ nozzles. The co-ordinate system (NB origin at throat geometric 
centre) used to report measurements and CFD predictions is also shown. The high pressure air supply pipeline consisted of a $75 \mathrm{~mm}$ round pipe; a round to rectangular transition duct $(75 \mathrm{~mm}$ diameter to $25 \mathrm{~mm}$ high $\mathrm{x} 91.6 \mathrm{~mm}$ wide) $275 \mathrm{~mm}$ long was attached to the pipeline and was followed by a straight rectangular duct of $677 \mathrm{~mm}\left(29.5 \mathrm{D}_{\mathrm{h}}\right)$ length to which the nozzles were connected using the flange shown in Fig.1. Optical access windows were introduced into the side and upper wall of the nozzle supply duct at a distance of $154 \mathrm{~mm}\left(6.73 \mathrm{D}_{\mathrm{h}}\right)$ upstream of the nozzle throat plane and within the straight rectangular section to allow measurement of the wall boundary layer that had built up in the supply duct. LDA measurements along the major and minor duct axes showed that the $99 \%$ boundary layer thickness was $5.5 \mathrm{~mm}$ on both walls; the mean velocity followed a $1 / 9^{\text {th }}$ power law velocity profile and data for axial Reynolds stress matched closely classical measurements for a zero pressure gradient boundary layer. The availability of this information allowed this location to be treated as the nozzle inlet plane in the CFD calculations reported below.

\section{Instrumentation}

Schlieren flow visualisation and two-component LDA mean velocity and turbulence measurements were conducted throughout the near-field region of the jet plume. The Schlieren unit utilised a rainbow filter instead of a knife-edge; undeflected light showed yellow, deflected light red in expansion and green in compression regions. Schlieren pictures were taken of the major and minor axis planes by rotating the nozzle. The DANTEC LDA system was used in backscatter mode and contained an $\mathrm{Al}_{2} \mathrm{O}_{3}$ solid particle generator $(0.3 \mu$ m median diameter $)$ to seed the flow. The LDA measuring volume dimensions $(\Delta \mathrm{x}, \Delta \mathrm{y}, \Delta \mathrm{z})$ were $0.076 \mathrm{~mm}, 1.254 \mathrm{~mm}$ and $0.076 \mathrm{~mm} ; 20,000$ validated samples or 20 seconds sampling time (whichever fulfilled first) was found suitable for capture of smooth, repeatable statistics. No corrections were made for sampling bias, rather associated errors were minimised by using high data rates compared to velocity fluctuation levels; samples were gathered at fixed time intervals (data rate 2 $\mathrm{kHz}$ ). The measurement uncertainty for mean velocity/rms values was estimated as $+/-2 \%$ and $+/-5 \%$.

\section{III.Computational Modeling}

\section{A. CFD Code, Numerical Details, Turbulence Model}

Prediction of un-scarfed round and rectangular jets has already been considered in the published literature, in particular to establish the accuracy of predicting the potential core length. For axisymmetric jets Georgiadis and DeBonis $^{27}$ presented an extensive review of RANS capability for potential flow length prediction. The main 
conclusions were: (i) standard two-equation closures consistently over-predict potential core length due to inhibited initial turbulence growth rate, and also display too rapid initial centreline decay, (ii) modifications to improve nearfield jet mixing accuracy had variable results (the modified $\mathrm{k}-\varepsilon$ model of Thies and $\mathrm{Tam}^{28}$ did improve core length prediction, but the downstream axial decay was then significantly too slow). Wang and McGuirk $^{29}$ have demonstrated that if careful attention is paid to initial conditions and to sub-grid-scale modelling, the Large Eddy Simulation (LES) approach can predict potential core length accurately for clean rectangular supersonic jets. LES is, however, an expensive methodology for routine design. Given that no computational investigation has been carried out on scarfed nozzle jets, the objective of the CFD work here was to assess the capability of a standard RANS closure to predict the changes in flowfield introduced by scarfing, accepting the known deficiency of RANS for potential core length prediction. Only steady RANS solutions were attempted here. As described below, efforts were undertaken to ensure the detailed measurements were carried out at NPRs which avoided intense screech. If strong screech is present, the interaction between unsteady motions and the mean field means an Unsteady RANS or potentially LES CFD approach would be necessary. The present investigation was considered worthwhile to examine the capabilities of steady RANS and an industry-standard turbulence model for the test conditions selected.

The Rolls-Royce Hydra CFD code (Crumpton et al..$^{30}$ ) was used in the present work. This is is a compressible, density-based code, which adopts unstructured finite-volume discretisation (on node-centred median-dual cells). Discretisation of the inviscid fluxes corresponds to central differencing plus $4^{\text {th }}$-order smoothing; monotonic resolution of sharp gradients is obtained by constructing the smoothing operator to include a blend of $2^{\text {nd }}$ - and $4^{\text {th }}$ order differences and a non-linear limiter. A multi-grid method parallelised method is adopted to ensure high efficiency; the message passing implementation is described in Hills ${ }^{31}$. The equations solved are the standard Favreaveraged Reynolds-Averaged Navier-Stokes equations for mass, momentum and total enthalpy; auxiliary algebraic equations to calculate temperature from total enthalpy (for use in the ideal gas relation to evaluate the pressure) complete the set. Finally, the turbulence model adopted to evaluate the turbulent momentum and enthalpy fluxes was the Spalart and Almaras ${ }^{32}$ 1-equation eddy viscosity model commonly used in aerospace applications. Preliminary calculations were performed for a clean nozzle NPR $=2.5$ case with both k- $\varepsilon$ and S-A models. Both models predicted the same shock cell number with similar amplitudes. For potential core length predicted values were $7.2 \mathrm{D}_{\mathrm{h}}(\mathrm{S}-\mathrm{A})$ and $8.6 \mathrm{D}_{\mathrm{h}}(\mathrm{k}-\varepsilon)$ compared to a measured value of $\sim 6 \mathrm{D}_{\mathrm{h}}$; since the S-A model produced a more 
accurate estimation (although still overpredicted as expected), this model was retained in all further calculations The high Reynolds number form of the model was applied, using a wall-function approach near all solid surfaces.

\section{B. Solution Domain and Mesh}

The same solution domain was chosen for both clean and scarfed nozzles; both designs are symmetrical about the z-axis and thus a half nozzle geometry was chosen for meshing (Fig.2). A short section of the rectangular inlet air supply duct to the nozzle was included in the geometry to allow measured inlet condition information to be applied, the nozzle inflow plane was thus at $\mathrm{x} / \mathrm{D}_{\mathrm{h}}=-6.73$.

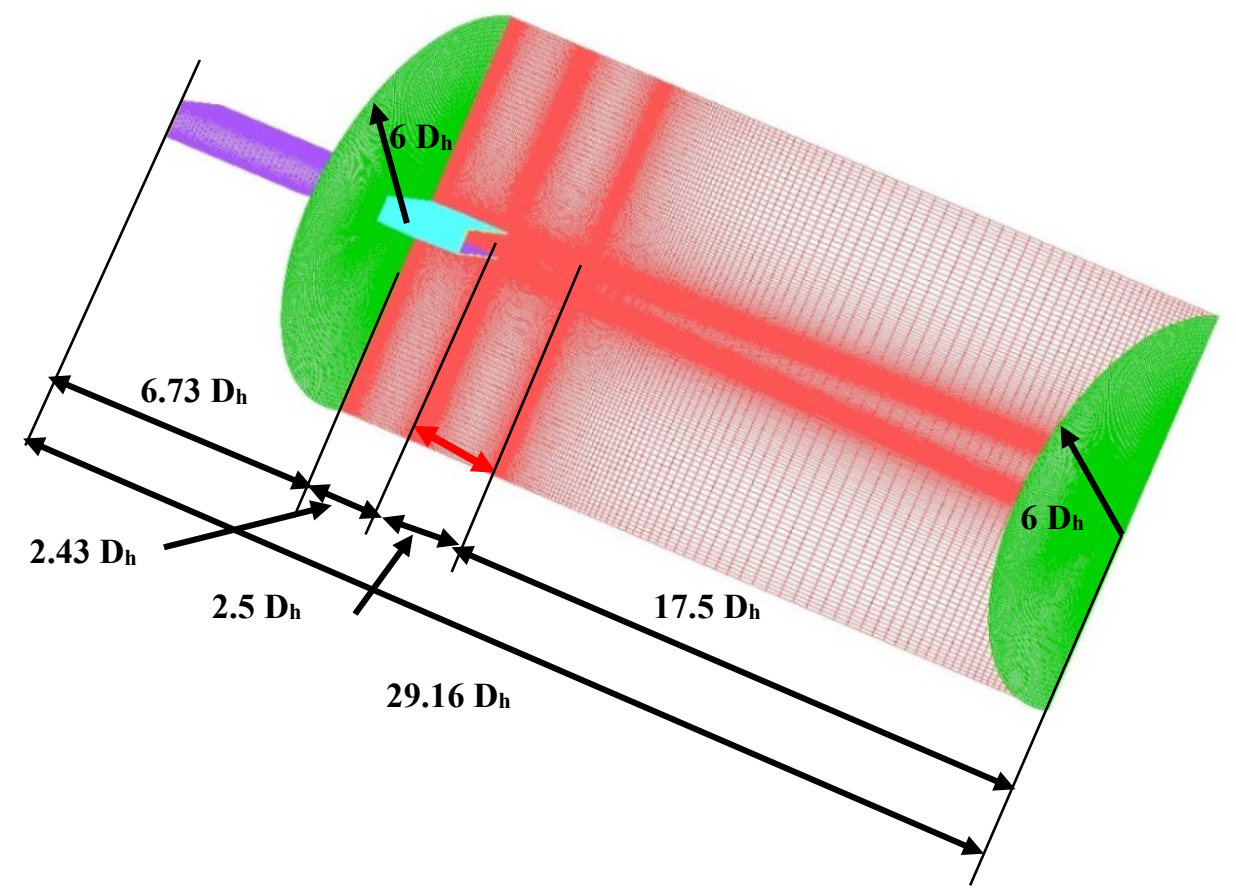

Fig. 2 Computational solution domain and mesh on the $y / D_{h}=0$ plane (clean nozzle)

The spread of the jet due to entrainment was visualised for both nozzles using Schlieren imaging for a range of NPRs over a distance of $\sim 20 \mathrm{D}_{\mathrm{h}}$ downstream of nozzle exit. This allowed estimation of the size of computational volume external to the plume to allow unconstrained ambient entrainment to occur without but minimising the external region mesh required. Following Babu and Manesh $^{33}$ a short 'buffer' region was included upstream of the nozzle to enable smooth merging of the external entrainment flow induced (effectively a small 'co-flow' is created); the inlet plane for the external region was thus placed at the nozzle throat axial location $\left(\mathrm{x} / \mathrm{D}_{\mathrm{h}}=0\right)$ so any upstream entrainment could adjust before encountering the jet. The outer boundary of the external region was fixed at a radius 
of $6 \mathrm{D}_{\mathrm{h}}$ from the nozzle centreline, and the downstream outflow exit boundary was at $\mathrm{x} / \mathrm{D}_{\mathrm{h}}=22.43$. Fig. 2 illustrates the solution domain and non-uniform mesh spacing used to ensure adequate resolution in regions of expected high velocity gradient, particularly over the scarfed nozzle exit plane. To maximise grid quality, a structured hexahedral mesh with 33 blocks was generated. Optimisation of mesh smoothness between blocks was given special attention particularly at the nozzle exit plane and over the initial $10 \mathrm{D}_{\mathrm{h}}$ axial distance. To choose the mesh density an offdesign (over-expanded) case was considered (to ensure shock cells were present). Mesh number was increased from an initial grid of $1.5 \times 10^{6}$ nodes until: (i) the amplitude of velocity oscillations in the jet core, and (ii) the jet potential core length, changed by less than $5 \%$, leading to ta final mesh size of $4.28 \times 10^{6}$ cells.

\section{Boundary Conditions}

At the nozzle inlet plane for each test case NPR a specified total pressure distribution was applied using the nozzle inlet measurements to include the low total pressure boundary layer regions, with uniform total temperature of $\mathrm{T}_{0}=288 \mathrm{~K}$; static pressure was extrapolated upstream from the first mesh points inside the solution domain and used to calculate the mean velocity (assuming axial flow). The turbulent eddy viscosity in the Spalart-Almaras model at this plane was set at $20 \mu_{\text {mol }}$. Symmetry conditions were used on the plane $y / D_{h}=0$; on the 'co-flow' inlet plane, radially outer, and downstream outlet planes constant static pressure and temperature conditions were applied. The static pressure was set equal to ambient pressure on the radial outer and downstream outlet planes but slightly higher ( $\sim 50$ Pascal) on the 'co-flow' inlet plane to provide a small entrainment flow; the turbulent viscosity on the co-flow inlet plane was set at $2 \mu_{\mathrm{mol}}$.

\section{IV.Test Conditions and Datasets}

Selected parameters for LDA measurement were mean and turbulent rms velocities in the $\mathrm{x}$ - and $\mathrm{z}$-directions $(U$, $u-r m s, W, w-r m s)$ and the turbulent shear stress $\left(\overline{u^{\prime} w^{\prime}}\right)$. These are presented in non-dimensional form $\left(U^{*}=U / U_{r e f}\right.$, $\left.u^{*}=u-r m s / U_{r e f}, w^{*}=w-r m s / U_{r e f}, u w^{*}=\overline{u^{\prime} w^{\prime}} / U_{r e f}^{2}\right)$; the reference velocity was the measured centerline velocity at the nozzle inlet plane for each NPR. Schlieren visualisation was first used for NPRs 1.8-5.0 to identify design points for both nozzles. For the clean nozzle NPR $=3.5$ was the most shock free condition; this reduced to 3.15 for the scarfed nozzle due to different losses and changed expansion conditions introduced by the scarfed geometry. Three operating conditions were then selected for detailed measurements: over-expanded NPR $=2.5$, design NPR $=$ 3.5(clean) 3.15 (scarfed), and under-expanded NPR $=4.0$; the over- and under-expanded NPR values were 
purposely chosen to avoid the peak screech NPR condition. For the clean nozzle, velocity traverses along y and $z$ axes (35/50 measurement points) were made at 16 axial stations between $\mathrm{x} / \mathrm{D}_{\mathrm{h}}=2.93-12.43$. A centerline traverse $(60$ points) up to $\mathrm{x} / \mathrm{D}_{\mathrm{h}}=17.93$ was also made. For the scarfed nozzle 4 planes were selected for study: $3 y$-z planes (half-planes: $\left.y / D_{h}<0.0\right)$ at $x / D_{h}=4,7$ and 12. In addition, a single $x-z$ plane $\left(y / D_{h}=0.0\right)$ was measured, and a total of 79 measurement points covering $1.8<\mathrm{x} / \mathrm{D}_{\mathrm{h}}<24.0$ captured the centerline development (the cut-back nozzle exit allowed measurements to start inside the scarfed nozzle).

\section{V.Results and Discussion}

\section{A. Schlieren Images}

Fig. 3 (left) presents 5 minor axis plane Schlieren images of the clean nozzle flow at NPRs between 2.5 and 5.0, and 2 major axis views at over- and under-expanded conditions. The short black lines at the bottom indicate axial spacings of $D_{h}$. At NPR $=2.5$ an over-expanded pattern appears, with the terminating normal shock at the divergent duct exit just visible bending out into the plume. At NPR $=3.0$, the strength of the compression region decreases and oblique waves appear. A much reduced wave amplitude appears for NPR $=3.5$, confirming this is close to the clean nozzle design NPR (which is lower, probably around 3.4, although no measurements were made to confirm this). Under-expanded oblique waves of increasing strength and axial extent are observed for NPR=4.0 and 5.0. The change in colour of the first wave system from green at NPR $=3.0$ to red at 4.0 is further evidence that these lie either side of the fully expanded condition. The images display a symmetric structure with strong expansion and compression regions, which weaken axially due to imperfect reflection of pressure waves from the thickening shear layer at the jet/ambient boundary. The major axis view for the over-expanded NPR $=2.5$ indicates a strongly $2 \mathrm{D}$ spanwise uniform wave pattern over the central $80 \%$ of the major axis; at the under-expanded condition a mixed wave pattern appears - a central 2D system for 3 cells with oblique wave pattern superimposed, which originates from the flow turning inside the nozzle and the nozzle corners. Note the jet width appears to decrease in the major axis direction at NPR $=5.0$, which may be evidence of the start of a mild axis-switching process, the over-expanded major axis view shows much less width decrease. 

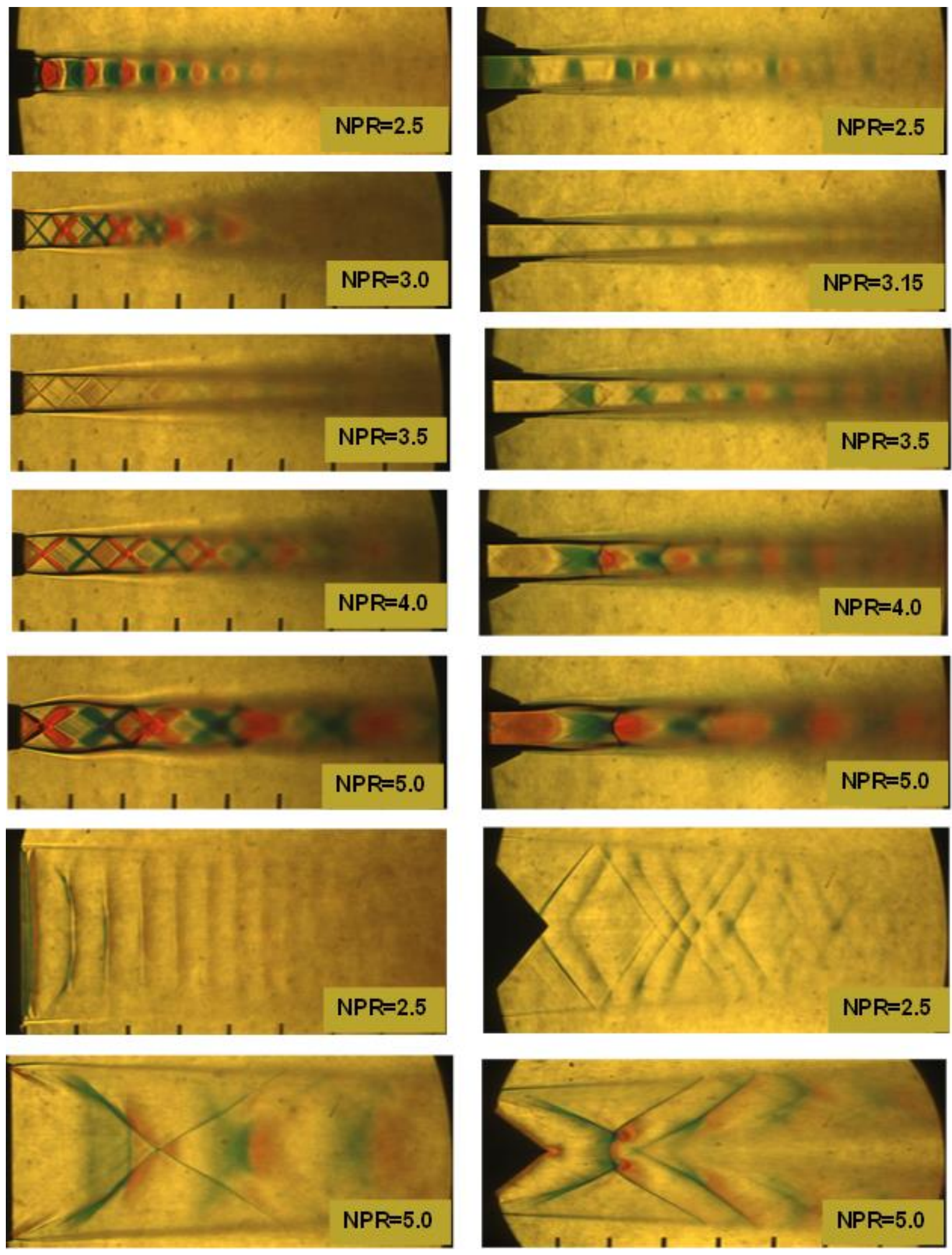

Fig. 3 Side and top (two bottom photos) Schlieren images of clean (left) and scarfed jet plumes (right) 
Finally, the minor axis view for NPR $=3.0$ indicates a wider and more diffuse outer region of the plume (from $\sim 3 \mathrm{D}_{\mathrm{h}}$ downstream of nozzle exit) in comparison to smaller/larger NPRs. This is evidence of transverse jet flapping caused by screech, which was observed to be strongest at NPR $=3.0$. Videos of the plume showed the upstream wave structures were caused to oscillate transversely (z-direction) and at this peak screech intensity the amplitude was large enough that interaction with the overall mean flow behaviour was clearly observed. As the NPR increased or decreased away from NPR $=3.0$ screech amplitude decreased rapidly. NPR $=2.5, \mathrm{NPR}=3.5$, and NPR $=4.0$ were chosen as the over-, (close to) design, and under-expanded conditions at which the screech was weak enough not to affect the mean flow. Measurements (see below) confirmed that, at these chosen conditions, although effects of weak screech could still be seen in the unsteady motion fluctuating statistics within the potential core, there was no evidence of this in turbulence stress measurements within the jet shear layers which control the mixing of mean momentum.

Fig. 3(right) provides Schlieren images for the scarfed nozzle over the same NPR range, indicating a strong effect on shock cell structures. Scarfing causes laterally variable expansion inside the nozzle as the axial length of divergence varies spanwise (y-direction). The scarfed nozzle design NPR is lower than for the clean nozzle, as shown by the NPR $=3.15$ image, which shows an essentially shock free flow. All minor axis shock cell images are less sharp than for the clean nozzle. This is caused by interaction between extra oblique shocks from the angled nozzle lip body (which allows substantially more flow turning) and the line-of-sight lateral averaging of the more 3D wave structures by the Schlieren technique; these changes are mostly associated with the near nozzle exit region. The major axis view at NPR $=5.0$ indicates that all signs of axis-switching have now disappeared as the lateral jet edge displays expansion rather than contraction, another change induced by scarfing. There were also no indications of strong screech at any NPR for the scarfed nozzle; this is consistent with the observation of $\operatorname{Raman}^{20}$ that scarfing shifts the onset of screech to higher NPR, in this case above the highest NPR tested.

\section{B. LDA Measurements}

\section{(i) Clean Nozzle Plume Development}

Figs. 4 and 5 present the development of non-dimensional time-averaged $U^{*}, u^{*}$ and $w^{*}$ rms along the nozzle centerline for the clean nozzle $(\mathrm{CN})$ at all 3 NPR conditions (scarfed nozzle (SN) results also shown - discussed in the following section). For the over-expanded case Fig 4(top) indicates that a curved shock exists at nozzle exit and thus subsonic velocities are measured just downstream of exit. The flow then rapidly accelerates and undergoes 
pressure-wave induced oscillations which have significant amplitude (initially $\sim 50 \% U_{\text {ref }}$ ). If the jet is improperly expanded, the presence of oscillations makes potential core length identification difficult. The velocity about which
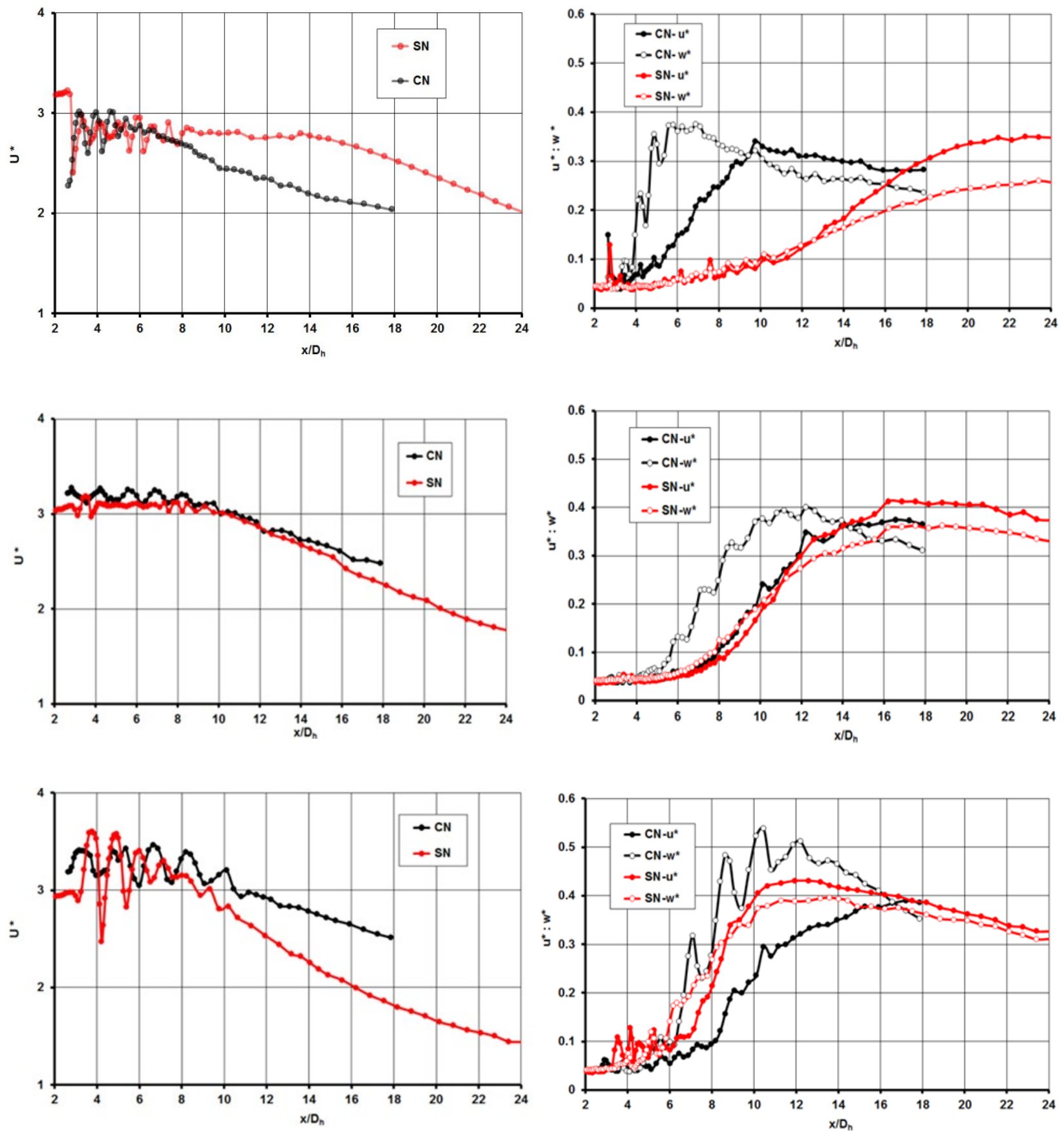

Fig. 4 Mean axial $\left(U^{*}\right)$ velocity plume centreline, clean and scarfed nozzles NPR: top 2.5, middle 3.5(CN)3.15(SN), bottom 4.0

Fig. 5 Axial $\left(u^{*}\right)$ and transverse $\left(w^{*}\right)$ rms plume centreline, clean and scarfed nozzles NPR: top 2.5, middle 3.5(CN)3.15(SN), bottom 4.0 
the decaying oscillations are symmetric has here been taken as the core velocity of the fully expanded jet. Using this definition, the potential core length (calculated from nozzle exit, which is located at $x / D_{h}=2.43$ ) for the overexpanded condition is shortest at $4.3 \mathrm{D}_{\mathrm{h}}$. At the (close to) design NPR (Fig. 4(middle)) much reduced oscillations are observed (only $\sim 15 \% U_{\text {ref }}$ ) and the core length increases to $5.5 \mathrm{D}_{\mathrm{h}}$. Under-expanded flow (Fig. 4(bottom) sees the oscillation amplitude increase again and core length grows to $6.5 \mathrm{D}_{\mathrm{h}}$. At this latter condition small oscillations are seen downstream of the potential core end after velocity decay has begun. Little difference is observed in the initial centreline velocity decay rate after the end of the potential core between the 3 NPRs studied.

Centreline clean nozzle turbulence measurements (Fig.5) show transverse fluctuations $\left(w^{*}\right)$ are initially larger than axial $\left(u^{*}\right)$ at all NPRs, particularly at off-design conditions, but also at NPR $=3.5$ since this is not quite at the design condition. The dominant strain rates occur in shear layers and imply that turbulence production is largest for $u^{*}$, which would thus be expected to be greater than $w^{*}$. The cause of this centreline anomaly is the effect of the mild screech-induced transverse jet flapping, which adds a periodic unsteady contribution to the transverse turbulence fluctuation. A similar relationship between axial/transverse fluctuations was observed in Alkislar et al. ${ }^{18}$ and was confirmed as transverse movement of the oblique shock/expansion wave pattern using phase-locked measurements. The peaks in $w^{*}$ are co-incident with the location of strong pressure wave interactions. Note that these effects of screech are only visible within the potential core itself, for all NPRs as soon as the jet shear layers grow to reach the centreline the expected normal stress relationship of $u^{*}>w^{*}$ is seen, confirming that only weak screech effects are present and only within the inviscid core, influencing potential core fluctuation measurements but not affecting important mean momentum mixing regions.

Figs. 6 and 7 provide examples of clean nozzle measured axial velocity and turbulent shear stress profile data (Fig. 6 also contains CFD results, to be discussed later); in both cases minor axis data at 3 axial stations are provided. Good symmetry is displayed; in Fig.7 the two zones of high shear stress separated by a reducing zero shear region clearly identify the inward growth of jet/ambient mixing. Note that in regions where centreline $w^{*}$ was influenced by jet flapping, the measured shear stress is zero indicating no correlation between axial turbulence and transverse flapping motions. Both velocity and stress profiles quantify the monotonic outward spread of the plume in the z-direction; the spreading rate is greatest for the over-expanded NPR, and approximately the same for design and under-expanded cases. For the selected locations, only at the under-expanded NPR (4.0) is evidence of centerline compression/expansion wave oscillations visible. 

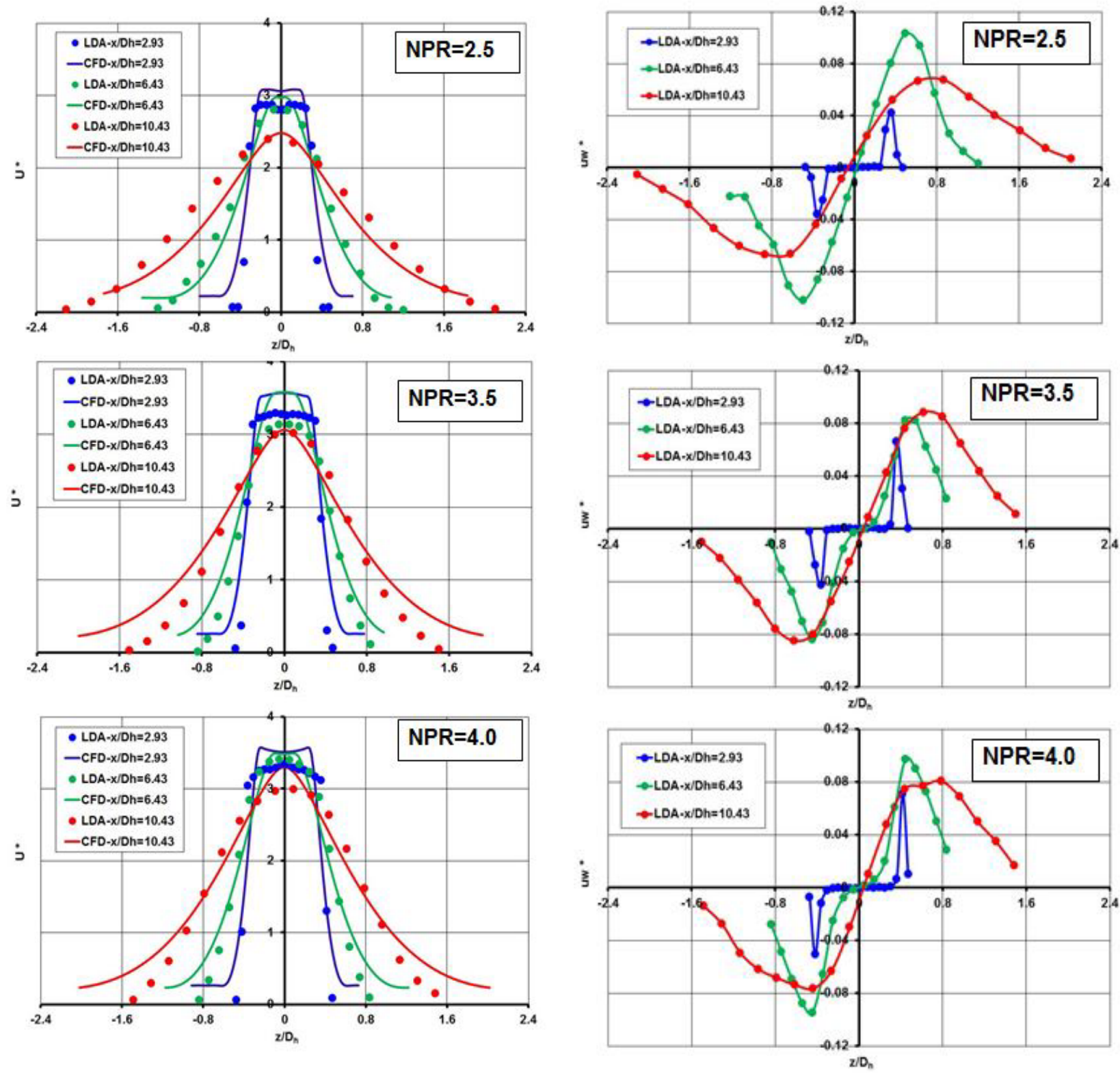

Fig. 6 Mean axial $\left(U^{*}\right)$ velocity on minor axis, clean nozzle

Fig. 7 Reynolds shear stress $\left(u w^{*}\right)$ on minor axis, clean nozzle

To display flow development in the major-axis y-direction, contour plots of $U^{*}$ and turbulent normal stresses are shown in Figs. 8 and 9. The presence of pressure waves in the jet core is easily identified in the $U^{*}$ plots. The velocity at nozzle exit increases with NPR, by $\sim 16 \%$ between over-expanded and (close to) design conditions and by a further 3\% between (close to) design and under-expanded NPR. In addition the larger downstream extent of the region where the static pressure adjusts to ambient in the under-expanded compared to the over-expanded flow is 
plain to see. The more 3D nature of this process for NPR $=4.0$ is illustrated well in Fig. 8 where the islands of higher velocity stretch across the whole inviscid core in the over-expanded flow, but two peaks either side of the centreline are observed for NPR $=4.0$ near $\mathrm{x} / \mathrm{D}_{\mathrm{h}}=5$. Further downstream, there is no evidence of axis-switching in the axial distance covered by measurements, but for NPRs 3.5 and 4.0 the appearance of 'saddle-shaped' velocity profiles is seen beyond $\mathrm{x} / \mathrm{D}_{\mathrm{h}} \sim 9.0$. Since screech effects on the mean velocity development are expected to be small, this is associated with the vortex ring mechanism observed in rectangular jets. Its absence for NPR $=2.5$ implies that the over-expanded case contains other sources of secondary motions (in the y-z plane), which are contrary to and counteract the vortex ring-driven secondary velocities.

The normal stress contours in Fig.9 show that in the major axis shear layer the axial stress is always larger than the transverse as expected from shear-generated turbulence arguments. This indicates the screech-induced transverse
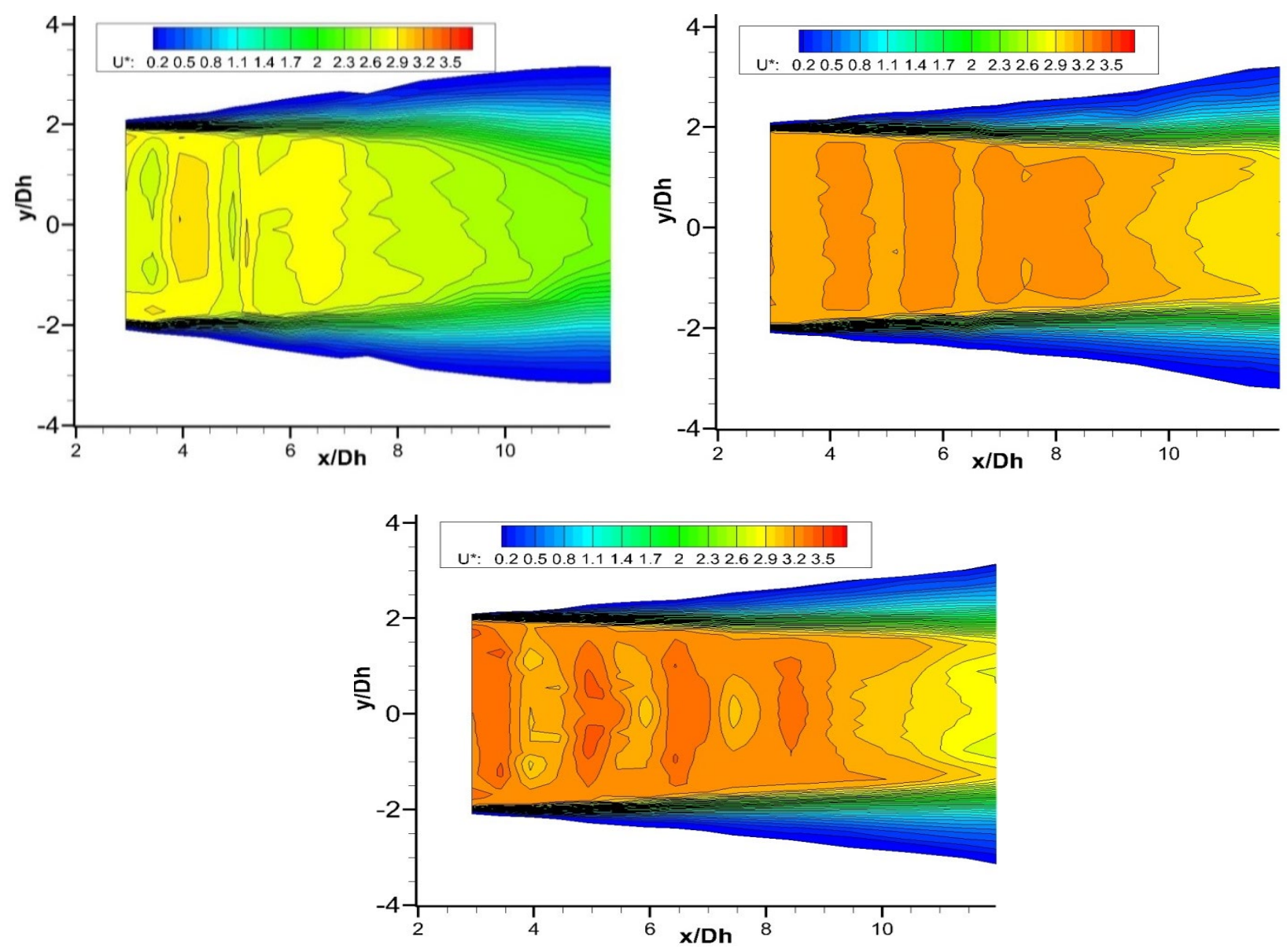

Fig. 8 Mean axial velocity $\left(U^{*}\right)$ contours on major axis, clean nozzle top left: $\mathrm{NPR}-2.5$, top right: $\mathrm{NPR}=3.5$, bottom: $\mathrm{NPR}=4.0$ 
flapping on the centreline within the inviscid core does not influence the jet/ambient momentum exchange process that controls mean flowfield development. Note also in Fig. 9, particularly at NPR $=4.0$, the double peak at the furthest downstream locations in the axial stress; this is clearly related to the saddle-shaped axial velocity profile, which creates both an outboard (jet/ambient) and inboard shear layer in the mean profile.
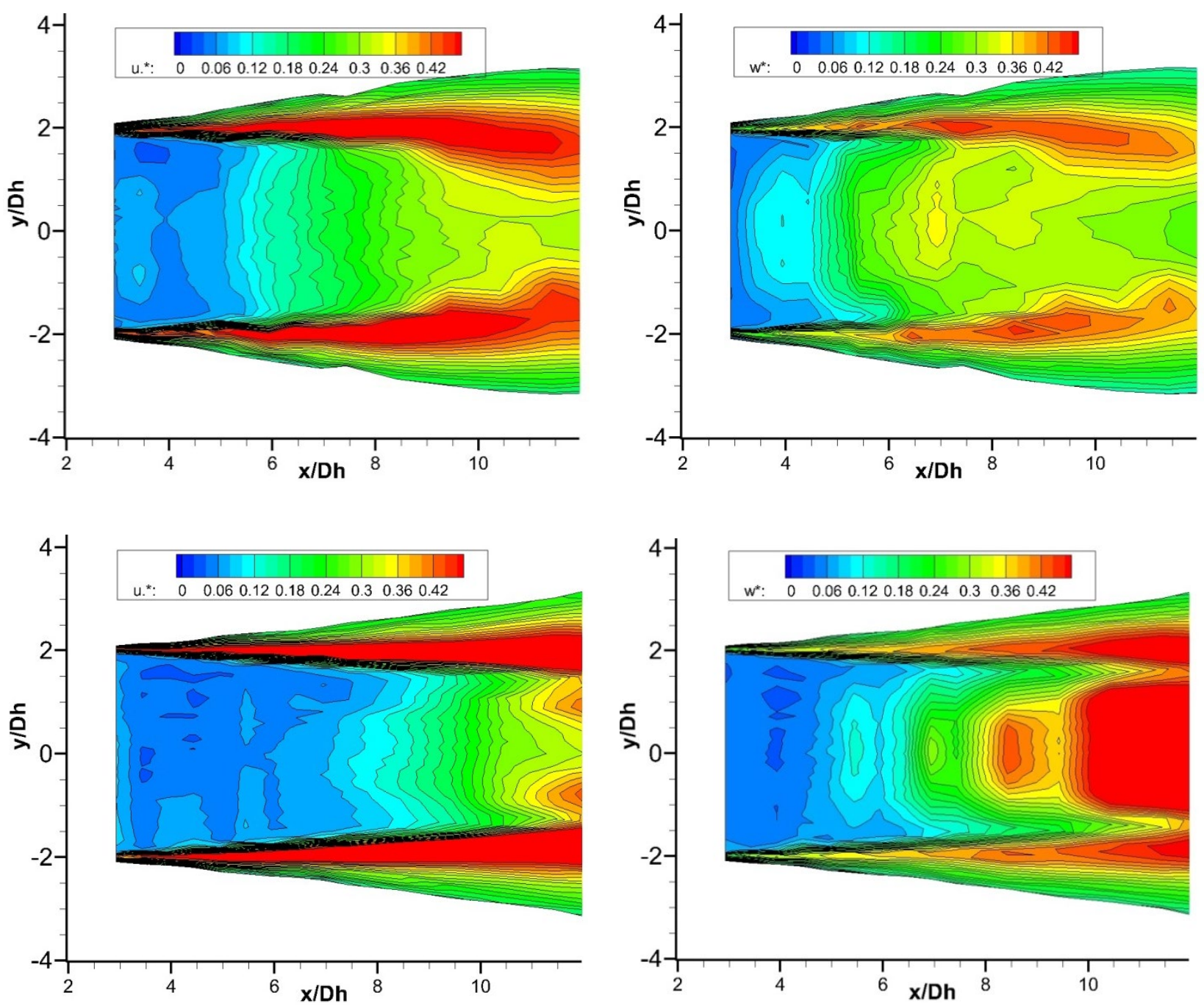

Fig. 9 Axial rms ( $u^{*}$, left) and transverse rms $\left(w^{*}\right.$, right) contours on major axis, clean nozzle top: $\mathrm{NPR}=\mathbf{2 . 5}$, bottom: $\mathrm{NPR}=\mathbf{4 . 0}$ 
(ii) Effect of Scarfed Nozzle Geometry on Plume Development

First observations on the different development of jets from clean and scarfed nozzles are made using the plume centreline development curves in Figs. $4\left(U^{*}\right)$ and $5\left(u^{*}\right.$ and $\left.w^{*}\right)$. At the design NPR only marginal changes are seen, with the small oscillations for the clean nozzle being even smaller in the scarfed case. As will become clear below, strong secondary flows associated with scarfing mean the maximum axial velocity location is no longer necessarily uniquely associated with the centreline as in the clean nozzle. These secondary flows may lead to bifurcation of the jet core and the peak velocity is then no longer on the centerline, since unmixed jet core fluid penetrates to a further downstream distance at off-centreline locations. It is thus unwise to define potential core length purely from centreline data for scarfed nozzles. Scarfed nozzle results at the design NPR (fig. 4(middle)) show that the location where centerline velocity begins to decay and the initial decay rate do not seem to have changed (note - the centreline nozzle exit plane is now at $\mathrm{x} / \mathrm{D}_{\mathrm{h}}=3.12$ for the scarfed nozzle). Larger differences are apparent in Figs. 4 (top) and (bottom) for over- and under-expanded conditions, but examination of spanwise characteristics below show that these are due to secondary flow effects rather than identifying the true jet potential core length. At NPR $=2.5$ velocity decay begins much further downstream compared to the clean nozzle $-10.5 \mathrm{D}_{\mathrm{h}}$ vs $4.3 \mathrm{D}_{\mathrm{h}}$, whilst the opposite occurs at under-expanded NPR- $5.3 \mathrm{D}_{\mathrm{h}}$ vs $6.5 \mathrm{D}_{\mathrm{h}}$. The reasons for these off-design changes are best explained on examination of plume axial cross-section contours as provided below. The initial decay rate has been affected by scarfing, particularly for the under-expanded NPR where a noticeable change is observed between $10<\mathrm{x} / \mathrm{D}_{\mathrm{h}}<20$. The scarf-induced change in centreline behaviour is also visible in the development of the normal stresses shown in Fig. 5. At the design NPR scarfed nozzle data follow development of the clean nozzle $u^{*}$ stress, for the over-expanded NPR the increase in turbulence with scarfing is shifted downstream relative to the clean nozzle, but upstream for the over-expanded case. It is also noticeable that the relative values of $u^{*}$ and $w^{*}$ are as expected from shear-generation considerations for all scarfed nozzle conditions with all shock location 'spikes' greatly reduced, indicating screech has been suppressed by scarfing.

A better impression of different clean vs scarfed flow development is gained by examining the minor axis plane planar contour plots in Fig.10. A slightly wider scarfed nozzle plume at NPR $=2.5$ but a narrower spread at the other two NPRs may be deduced from contour comparison in the furthest downstream region. The scarfed nozzle pressure adjustment regions extend further downstream for over-expanded flow, but less far at the under-expanded NPR. 

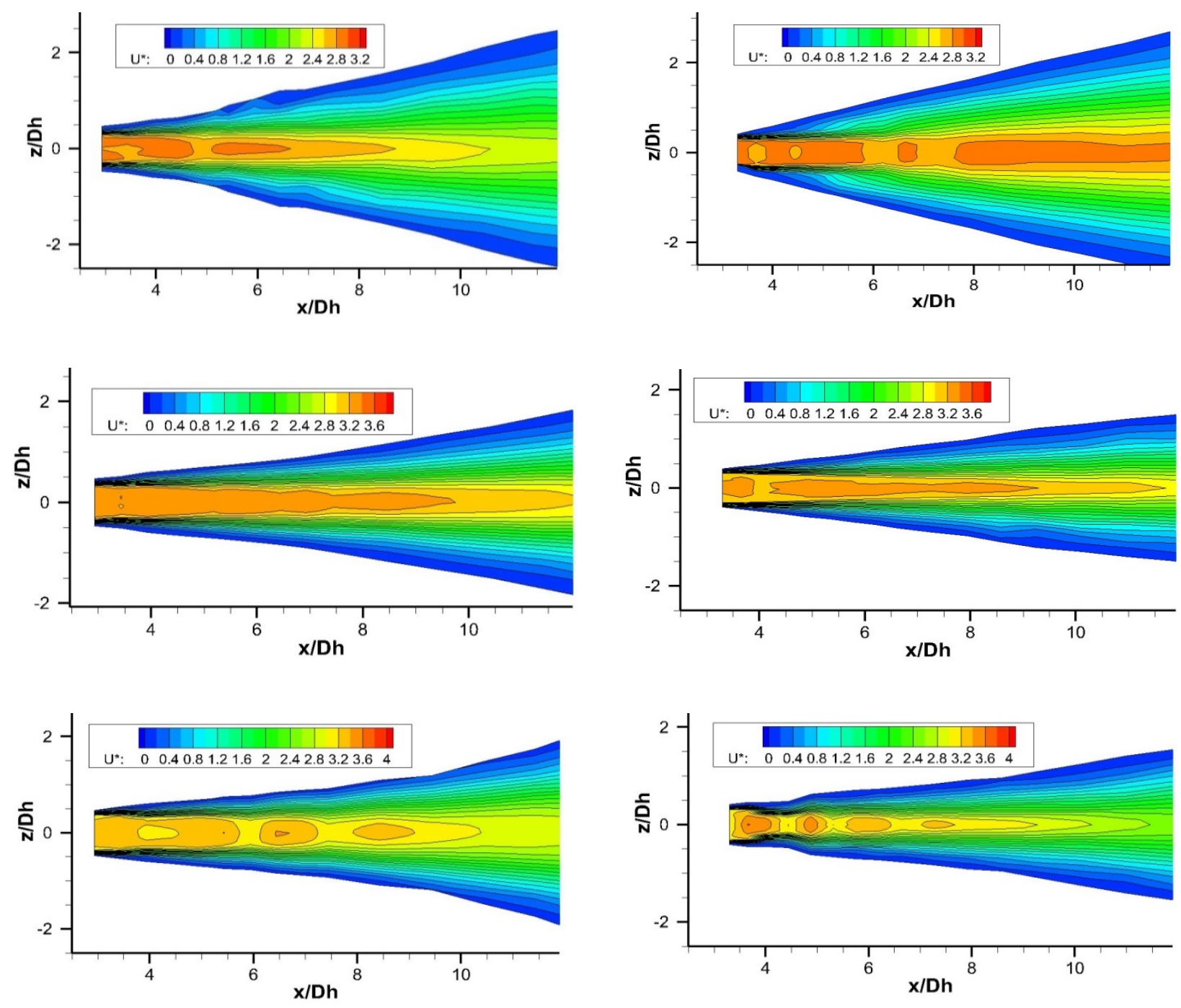

Fig. 10 Contours of axial velocity $\left(U^{*}\right)$ on plume minor axis plane clean nozzle (left) vs scarfed nozzle (right);

(top) $\mathrm{NPR}=2.5,($ middle) $\mathrm{NPR}=3.5 / 3.15$, (bottom) $\mathrm{NPR}=4.0$

The primary cause of different flow development is revealed in the constant-x plume cross-sections at the two offdesign NPRs in Fig. 11 (note CFD results also shown in this figure and are discussed in the next section). At the station closest to nozzle exit the rectangular shape of the nozzle exit is maintained for both NPRs, although some indication of scarf-induced secondary flow (y-z plane) effects may just be seen via contour distortions near the symmetry plane (both NPRs) and at the plume corners (NPR $=4.0)$. The jet boundary shape in these regions is affected by secondary motions (streamwise vorticity) as well as turbulent diffusion. For NPR $=2.5$ these two processes combine to cause radically different spreading rates in the two cross-stream directions. By $\mathrm{x} / \mathrm{D}_{\mathrm{h}}=12.0$ the cross-section aspect ratio has changed from 2:1 (half-section) to approximately 1:1, although still not overall 
axisymmetric. A small circular high velocity core region is surrounded by 4-lobe-shaped contours with maximum penetration on the major/minor axis planes. The plume edge has not penetrated any further in the major axis direction than its location at nozzle exit, whereas it has moved substantially in the minor axis direction.
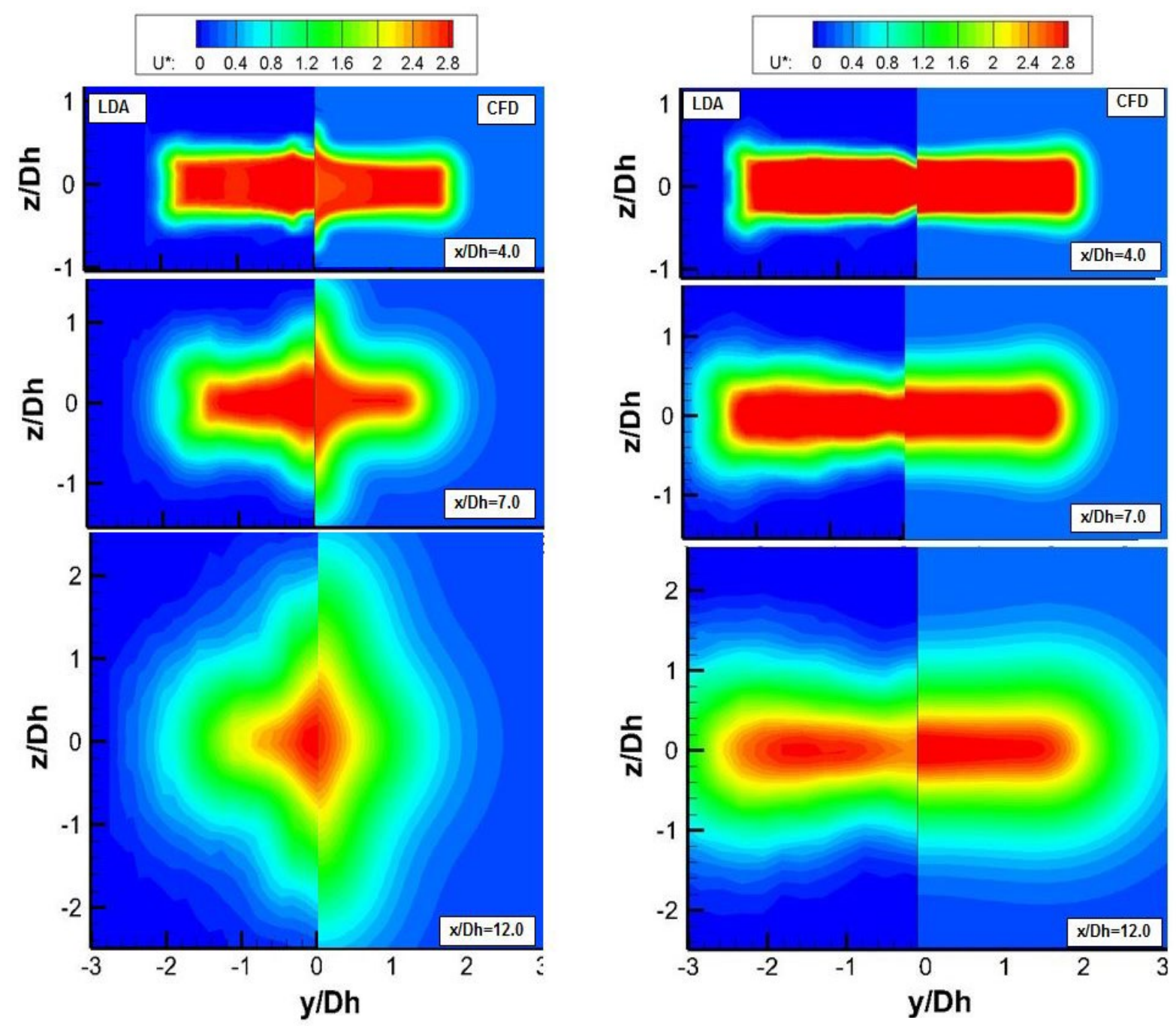

Fig. 11 Contour maps of axial velocity $\left(U^{*}\right)$ for scarfed nozzle: $\mathrm{NPR}=2.5$ (left), 4.0 (right) on planes $\mathrm{x} / \mathrm{D}_{\mathrm{h}}=4.0($ top $), 7.0$ (middle), $12.0($ bottom)

For the under-expanded flow the interplay between mixing and secondary velocity convection produces a completely contrasting result - the plume retains its rectangular-like shape for the whole downstream distance. plume growth occurs in both cross-stream directions, but at roughly similar rates to maintain the initial shape, with turbulent diffusion leading to rounded corners. In addition a bifurcation appears with two peaks of velocity observed either side of the centerline at $\mathrm{x} / \mathrm{D}_{\mathrm{h}}=12.0$. 
Finally, Fig. 12 shows that the development of the $u^{*}$ normal stress rms provides a similar picture of the distorting effect of the secondary motions. It is noticeable that the peak amplitude of $u^{*}$ has reached a maximum at $\mathrm{x} / \mathrm{D}_{\mathrm{h}}=7.0$ and then begins to decay for NPR $=2.5$, whereas for NPR $=4.0$ the peak value is maintained over the whole downstream length, with the high turbulence region thickening substantially. The explanation for these different behaviours is that the movement of the plume boundary due to secondary motion and turbulent spreading is coincident and reinforcing in the case of NPR $=2.5$ but contrary and cancelling for NPR $=4.0$.
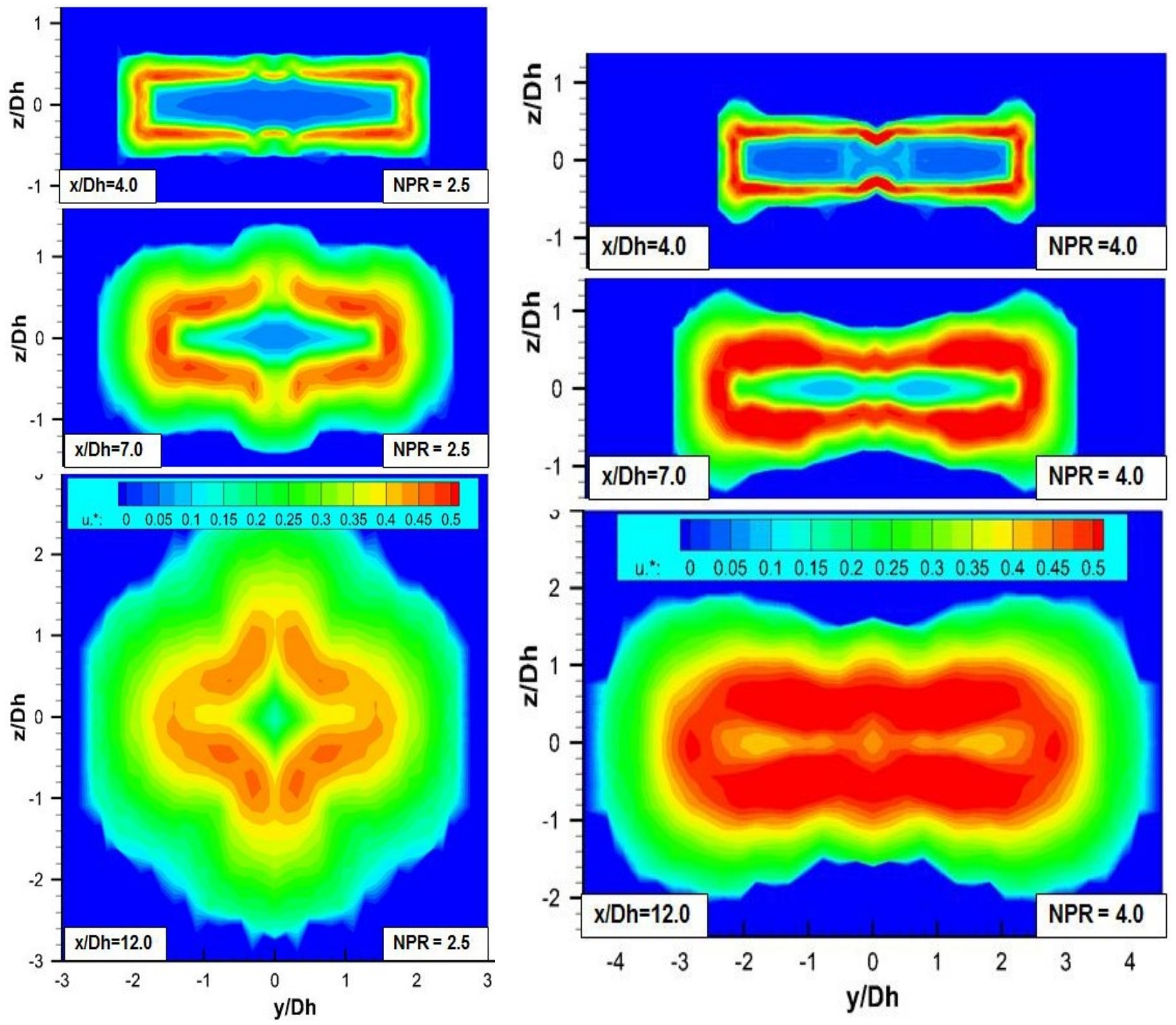

Fig. 12 Contour maps of axial $\left(u^{*}\right)$ rms velocity, scarfed nozzle for NPR $=2.5$ (left) and 4.0 (right) on planes $x / D_{h}=4.0($ top $), 7.0$ (middle), 12.0 (bottom) 


\section{B. CFD results}

CFD predictions of jet plumes from clean and scarfed nozzles are now presented, with emphasis given to offdesign NPRs since measurements showed this is where the largest effects of scarfing were observed. Fig. 13 shows comparison of clean nozzle LDA measurements and CFD predictions along the plume centreline. Agreement is generally reasonable. The appearance of a sharp drop in velocity at nozzle exit to (just) subsonic levels is captured well in the over-expanded case. The number and amplitude of shock cells is well predicted, although their location is shifted downstream for the over-expanded NPR. The potential core length is overpredicted (as expected for an eddyviscosity-based RANS turbulence model), particularly for NPR $=2.5$. However, the experimentally observed tendency for potential core length to increase between over- and under-expanded conditions is captured in the CFD results. The initial velocity decay rate is not changed appreciably by NPR and is close to that observed in experiments. However, the larger potential core error for NPR $=2.5$ causes downstream plume velocities to be over -predicted but under-predicted for NPR $=4.0$. Finally, to examine jet profile axial development, measurements and predictions on the minor axis plane are compared in Fig. 4 (similar characteristics seen for major axis plane development and thus not shown here). The agreement is again reasonable with a slightly too slow spreading rate for $\mathrm{NPR}=2.5$ and too rapid for NPR $=4.0$, consistent with the centreline results.

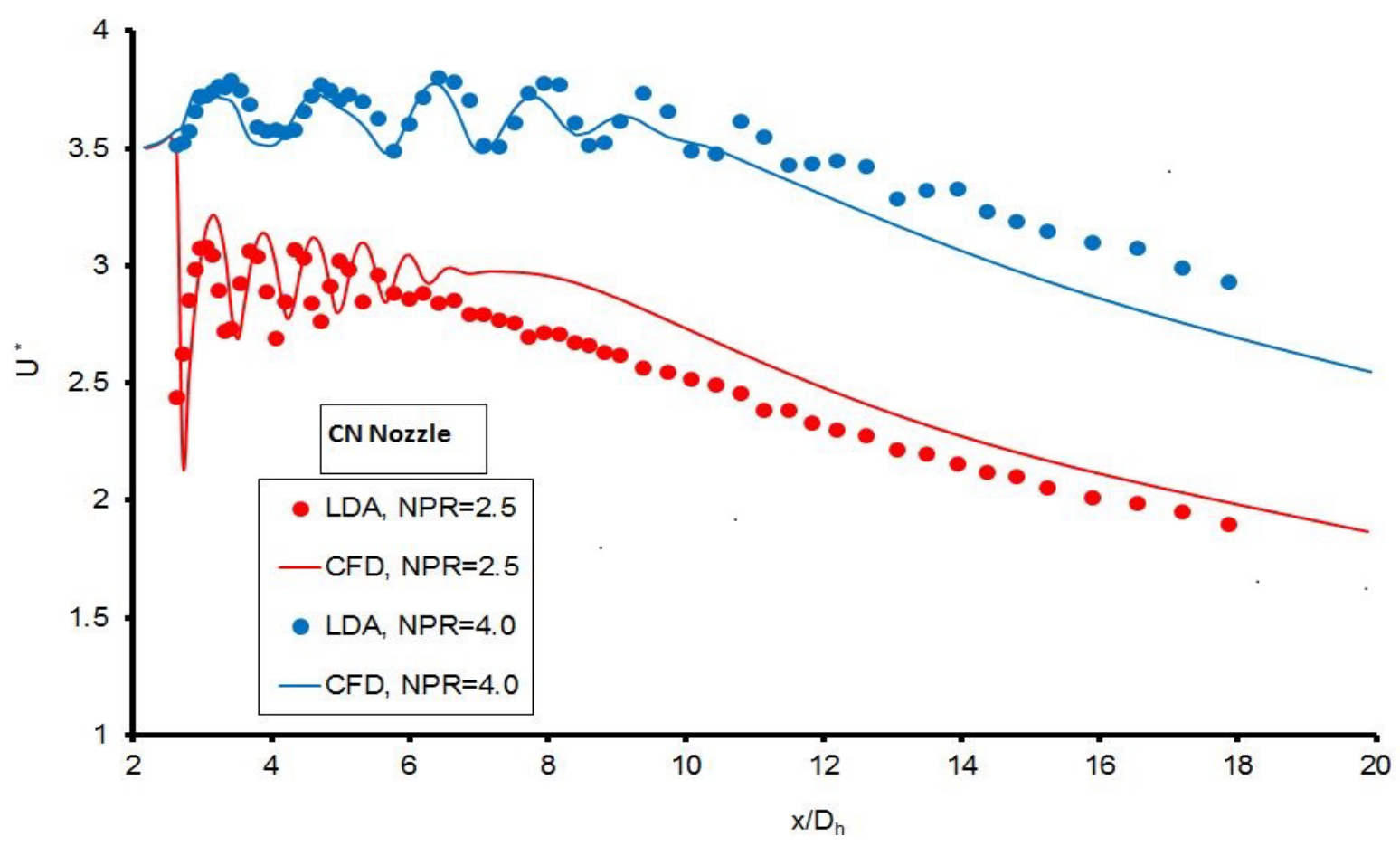

Fig. 13 Comparison of LDA and CFD for centreline axial velocity for clean nozzle 
Predictions for the scarfed case are compared with measurements for the two off-design NPRs in Fig. 11, focussing on plume cross-sectional shape change seen via axial velocity contour maps in 3 constant-x planes. The measured trend is captured well by CFD in that a 4-lobed shape is predicted to appear at over-expanded conditions whereas a rectangular shape is maintained in under-expanded flow. More detailed assessment leads to the conclusion that the secondary velocities which control the shape change are over-predicted at over-expanded conditions and under-predicted for under-expanded flow. Although CFD correctly predicts a 4-lobed shape for NPR $=2.5$, predicted secondary velocities are clearly too strong, since CFD shows an overshoot compared to measurements at $\mathrm{x} / \mathrm{D}_{\mathrm{h}}=12.0$ with the $\mathrm{z}$-direction size of the predicted plume incorrectly exceeding the y-direction size. The under-expanded case is also not exactly reproduced in CFD results since no evidence of bifurcation is shown in predicted velocity contours, unlike in the measured data. There was no evidence at further downstream locations of any predicted bifurcation, so it seems likely that the secondary velocities that cause the peak velocity to move off-centreline are under-predicted (see below). In addition to these global discrepancies, a local error appears with respect to the secondary velocities induced at the sharp central corner of the scarfed geometry. The contour distortions at the first measurement station are different in experiments and CFD. For over-expanded flow two outward-pointing peaks appear either side of the centreline in the experiments, whereas only a single peak on the centreline is seen in the CFD. Similarly, for under-expanded flow an inward-pointing distortion appears in measurements but is not seen in the CFD. These comparisons show that whereas the current RANS closure captures the trend of scarf effects on plume development at off-design NPRs qualitatively correctly, there is still a lack of predictive capability in terms of correct amplitude and local details of the scarf-induced secondary flows.

In spite of the differences noted above between predictions and measurements, CFD can still be usefully exploited to clarify the interacting mechanisms which cause scarfing to produce such different effects at over- and under-expanded conditions. Cross-plane secondary flows are driven by both static pressure gradients and turbulent mixing. For the clean geometry the nozzle exit static pressure is broadly uniform, although only at the design NPR is this at ambient pressure. Examination of CFD predicted clean nozzle exit static pressure at NPR $=3.5$ indicated the central $90 \%$ of the nozzle exit area was at $\sim 94 \% \mathrm{p}_{\text {ambient. }}$ Thin regions near the walls showed slightly lower pressure $\left(\sim 91 \% \mathrm{p}_{\text {ambient }}\right)$ but in general the close-to-ambient condition was observed. For NPR $=2.5$ the nozzle exit static pressure (again uniform over $\sim 90 \%$ of the area) was $\sim 66 \% \mathrm{p}_{\text {ambient, }}$, whereas at NPR $=4.0$ it was $\sim 107 \% \mathrm{p}_{\text {ambient }}$. 
Scarfed predictions for nozzle exit plane static pressure are presented in Fig.14. Note that what is shown is the static pressure over the angled nozzle exit. Thus the plane shown in Fig. 14 is canted backwards at $35^{0}$ to the x-axis, with the nozzle centreline on the left (axial location: $x / D_{h}=3.12$ ) and the nozzle side-wall (white rectangle) on the right (axial location: $x / D_{h}=1.72$ ). The angled exit area means that pressure exchange between internal nozzle fluid and ambient fluid is able to occur over the entire axial distance between nozzle exit at the sidewall and at the centreline nozzle tip. In addition, since different expansion lengths are experienced by fluid on the centreline and fluid at the wall, the static pressure at these two locations will also clearly be different.
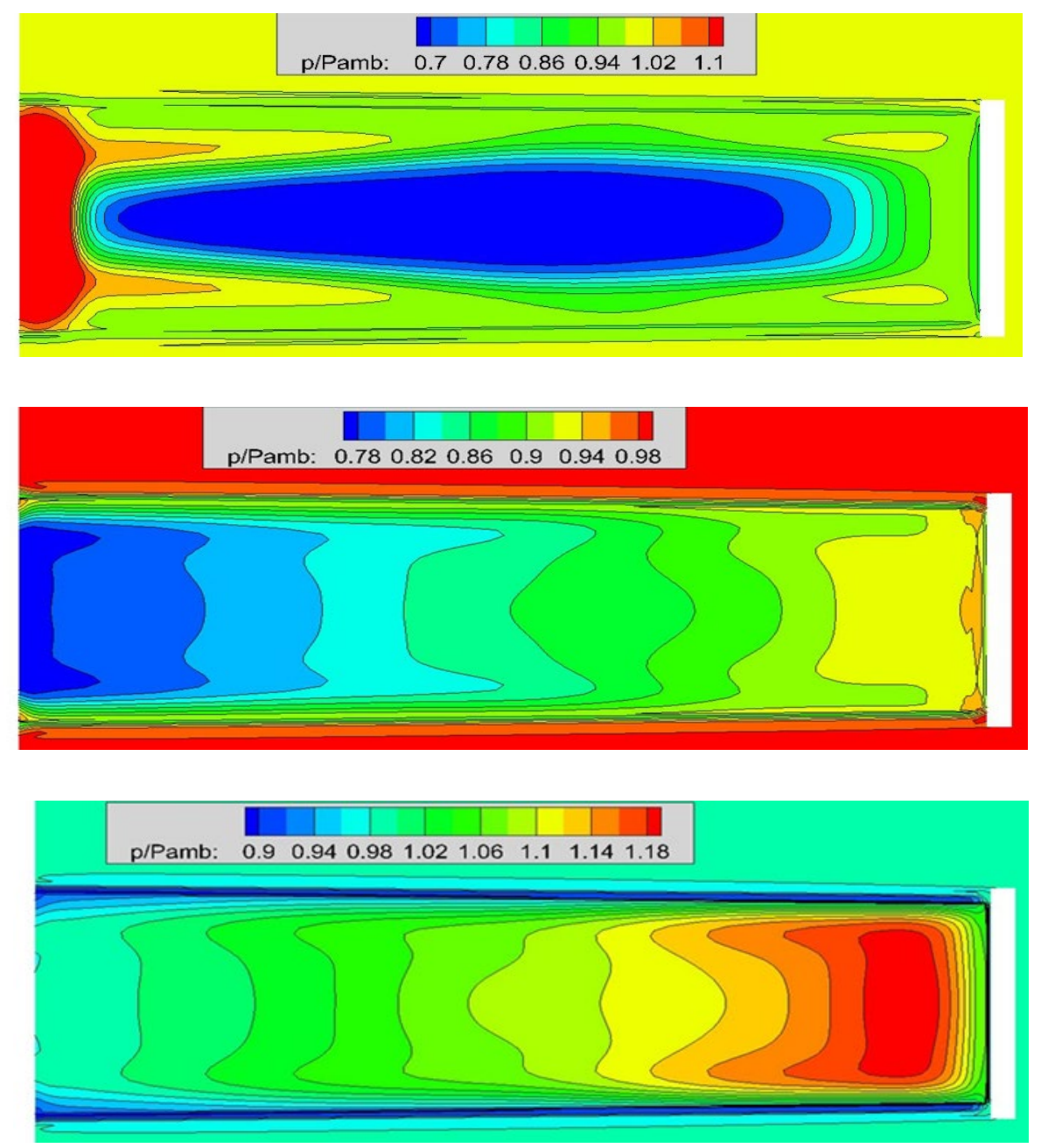

Fig. 14 CFD prediction of static pressure field on scarfed nozzle exit plane (top): $N P R=2.5,($ middle): $N P R=3.15,($ bottom $): N P R=4.0$

The pressure difference between internal nozzle fluid and ambient will of course drive cross-plane secondary flow. The predicted static pressure fields in Fig.14 indicate substantial pressure differences exist over the scarfed nozzle exit plane. At the design NPR the pressure is generally lower than ambient, particularly at the centreline. At 
the over-expanded NPR the pressure is again less than ambient but the pressure difference is now substantially larger. At the under-expanded NPR the pressure difference is predominantly positive, especially at the nozzle sidewall. These pressure differences will in particular drive flow in the spanwise negative y-direction at design and over-expanded NPRs, but in the positive y-direction at the under-expanded NPR. Pressure-driven secondary flows will be superimposed on those generated by the turbulent entrainment process, which in general will be directed from the ambient in towards the jet core. Fig. 15 illustrates the predicted secondary flow patterns (vectors formed from $y / z$ components only) at $\mathrm{x} / \mathrm{D}_{\mathrm{h}}=7.0$ for the two off-design NPRs for the clean nozzle (top) and the scarfed geometry (bottom).
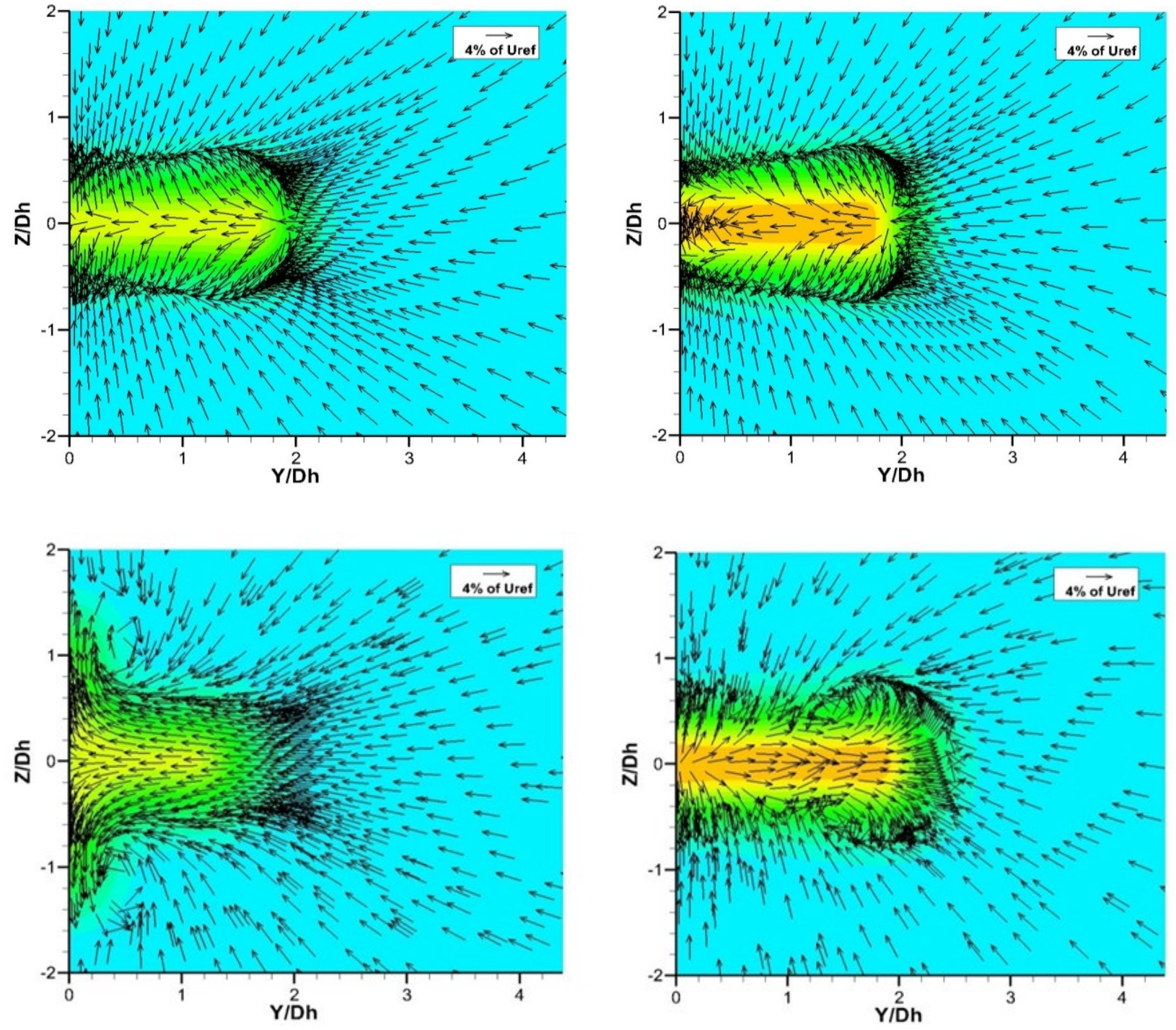

Fig. 15 CFD prediction of secondary velocity vectors on plane $x / D_{h}=7$, Top: clean nozzle, bottom: scarfed nozzle (left): NPR $=2.5$, (right): NPR $=4.0$ 
Clean nozzle results illustrate the expected vortex ring driven secondary flow pattern for a rectangular jet, which is (strongly) inwards towards the nozzle centre on the major axis and (weakly) outwards from the jet core towards the jet edge on the minor axis. Superimposed on this is the overall turbulent diffusion driven entrainment velocity (radially inward from ambient towards the jet centre). These mechanisms combine to form the secondary flow pattern seen in Fig. 15(top), which is generally similar at over- and under-expanded conditions

.Fig. 15(bottom) illustrates how this pattern changes due to scarfing at over-expanded NPR (left) and underexpanded NPR (right). In addition to the two mechanisms described above, a $3^{\text {rd }}$ mechanism is the pressure deficit (over-expanded) or excess (under-expanded) between the jet core and ambient. For NPR $=2.5$ this drives flow from the ambient into the jet core in the major axis direction, and for NPR $=4.0$ the reverse occurs. This $3^{\text {rd }}$ mechanism reinforces the vortex ring induced secondary velocity for NPR $=2.5$ but opposes it for NPR $=4.0$. The consequence is that the tendency for the secondary flows to change the rectangular shape of the jet is greatly enhanced for NPR = 2.5 but weakened for NPR $=4.0$. The flow patterns shown in Fig. 15 explain the predicted cross-sectional shapes seen in Fig. 11. For NPR $=2.5$ the interaction between minor axis outflow and inward entrainment flow creates a clockwise rotating vortex near the central symmetry plane in the upper half of the jet (and a reverse vortex in the lower half). This vortex is clearly responsible for the two lobes appearing in the z-direction in the upper/lower halves of the jet. The opposite is observed for NPR $=4.0$ where vortex ring-induced flows and scarf-induced flows oppose each other and almost cancel out. The interaction/impingement of these two flow mechanisms now creates just a small counter-clockwise vortex in the upper jet half at approximately $2 / 3$ rds of the jet width and the contours in Fig.11 retain their rectangular shape. The outward directed secondary flow on the major axis seen in Fig. 15 (bottom right) would result in the plume bifurcation seen in the scarfed experiments at the under-expanded NPR, but is clearly too weak to cause this to occur in the CFD predictions. However, it may be that, since grid independence checks were carried out for the clean nozzle only, insufficient resolution of the sharp central and nozzle edge corners in the scarfed geometry may have contributed to this under-prediction and further grid refinement studies would be useful.

\section{VI.Summary and Conclusions}

Two rectangular con-di nozzles with clean and scarfed exit planes were designed. Schlieren visualisation and LDA measurements were carried out to capture plume development in the near-field at over-expanded, (close to) 
design, and under-expanded conditions. RANS CFD studies using the Spalart-Almaras turbulence model were also completed for both clean and scarfed nozzle geometries at the same operating conditions.

Schlieren images for the clean nozzle showed the expected differences with NPR, with over-expanded flow producing 2D transverse pressure wave structures, and under-expanded conditions displaying stronger threedimensionality. Some evidence of screech-induced jet flapping in the minor-direction was observed and the NPRs selected for detailed measurements were chosen to avoid the region where screech was strong enough to influence mean flow development. The effect of scarfing on these patterns was to reduce the design NPR, to produce generally increased 3D wave patterns, and to suppress any occurrence of screech.

Detailed LDA measurements were provided along the centreline and for profiles on major/minor axes. For the clean nozzle, mild screech effects were observed via the excess of transverse over axial velocity fluctuations on the jet centreline. However, in the shear layers where momentum mixing dominated the jet development there was no evidence of significant screech effects. Measurements also showed that peak non-dimensional axial velocity at nozzle exit increased with NPR, indicating small changes in the nozzle discharge coefficient. Saddle-shaped velocity profiles were noted in the downstream region for the under-expanded case, but insufficient to cause axis switching. Scarfing produced a significant effect on jet centreline development; the location where velocity decay began was moved downstream for over-expanded flow but shifted upstream slightly at under-expanded NPR. Data on the plume cross-section revealed the strongest effect of scarfing was at off-design conditions, particularly for overexpanded flow where large plume cross-section distortion into a 4-lobd shape was observed.

For a clean nozzle the RANS CFD predicted flow development reasonably accurately, although the expected over-prediction of potential core length was observed. The effect of NPR on the developing plume cross-section for the scarfed nozzle at off-design conditions was reproduced but only qualitatively. At the over-expanded condition a 4-lobed shape was predicted but the strength of secondary velocities driving this was over-estimated. Examination of the predicted scarfed nozzle exit static pressure explained the very different behaviour at over- and underexpanded conditions. For the former the pressure-driven secondary velocities reinforced the secondary velocities that drove jet cross-section shape change, whereas they reduced these at the under-expanded NPR Given that the amplitude of the secondary velocities was not captured accurately by the RANS CFD applied here, further grid refinement studies are recommended for the scarfed nozzle case, and the present experimental data should be further 
explored using alternative RANS or LES turbulence closures to identify the optimum CFD approach for prediction of scarfed nozzle effects.

\section{VII.References}

1. Hiley, P. E., Wallace, H. W., Booz, D. E., "Non-axisymmetric nozzles installed in advanced fighter aircraft", AIAA Jnl. of Aircraft, Vol. 13, 1976, 1000-1006.

2. Shyne, R. J., "A survey of challenges in aerodynamic exhaust nozzle technology for aerospace propulsion applications”, NASA TM-2002-211977, Nov. 2002.

3. Gamble, E., Terrell, D., DeFrancesco, R., "Nozzle selection and design criteria", AIAA 2004-3923, 40"th AIAA/ASME/SAE/ASEE Joint Propulsion Conference, Fort Lauderdale, Florida, USA, July 2004.

4. Lamb, M., Taylor, J. G., Frassinelli, M. C., "Static internal performance of a 2D con-di nozzle with external shelf”, NASA TM 4719, Sept. 1996.

5. Mahulikar, S. P., Sonawane, H. R., Arvind Rao, G., "Infra-red signature studies of aerospace vehicles", Progress in Aerospace Sciences, Vol. 43, 2007, 218-245.

6. Bridges, J. E., "Noise of embedded high aspect ratio nozzles", NASA Fundamental Aeronautics Programme Technical Conference, Cleveland, Ohio, USA, March 2011.

7. Zaman, K. B. M. Q., "Flow-field surveys for rectangular nozzles”, AIAA 2012-6069, 50"th AIAA Aerospace Sciences Meeting, Nashville, Tennessee, USA, Jan 2012.

8. Dix, J., Saddington, A. J., Knowles, K., Richardson, M. A., "Infra-red signature reduction study on a small scale jet engine", The Aeronautical Journal, Vol. 109, 2005, 83-88.

9. Brown, A. C., "The effect of signature constraints on the F-117 configuration development", AIAA 2003-5761, AIAA Guidance, Navigation and Control Conference, Austin, Texas, USA, Aug. 2003.

10. Bridges, J., Wernet, M.P. "Establishing consensus turbulence statistics for hot jets", AIAA 2010-3751 16" AIAA/CEAS Aeroacoustics Conference, Stockholm, Sweden, June 2010.

11. Behrouzi, P., McGuirk, J. J., “Under-expanded jet development from a rectangular nozzle with aft-deck”, AIAA Journal, Vol. $53,2015,1287-1298$.

12. Hussain, F., Husain, H. S., "Elliptic jets: Part 1 - Characteristics of unexcited and excited jets", Journal of Fluid Mechanics, Vol. 208, 1989, 257-320.

13. Putnam, L. E., Mercer, C. E., "Pitot-pressure measurements in flow fields behind a rectangular nozzle with exhaust jet for free stream Mach numbers of 0.0, 0.6, and 1.2”, NASA Technical Memorandum 88990, 1986. 
14. Von Glahn, U. H., "Two-dimensional nozzle plume characteristics", AIAA 87-2111, 23 $3^{\text {rd }}$ AIAA Joint Propulsion Conference, San Diego, California, USA, 1987.

15. Veltin, J., McLaughlin, D. K., "Flowfield and acoustic measurements of rectangular supersonic jets", AIAA 2009-19, 47"th AIAA Aerospace Sciences Meeting, Orlando, Florida, Jan. 2009.

16. Zaman, K.B.M.Q., "Spreading characteristics of compressible jets from nozzles of various geometries", J. Fluid Mech., Vol. $383,1999,197-228$.

17. Krothapalli, A., Hsia, H., Baganoff, D., Karamcheti, K., "The role of screech tones in mixing of an under-expanded rectangular jet," Journal of Sound and Vibration, Vol. 106, 1986, pp. 119-143.

18. Alkislar, M. B., Krothapalli, A., Lourenco, M., "Structure of a screeching rectangular jet: a stereoscopic PIV study", J. Fluid Mech., Vol. 489, 2003, 121-154.

19. Valentich, G., Davis, T., Fernandez, E., Kumar, R., Alvi, F., Alphonso, M., Harris, C., "Characterisation of a supersonic rectangular jet over a range of test conditions”, AIAA 2015-0230, 53 ${ }^{\text {rd }}$ AIAA Aerospace Sciences Meeting, Kissimmee, Florida, USA, Jan. 2015.

20. Raman, G., "Screech tones from rectangular jets with spanwise oblique shock-cell structures", J. Fluid Mech., Vol. 330, 1997, 141-168.

21. Raman, G., “Advances in understanding supersonic jet screech: review and perspective”, Progress in Aerospace Science, Vol. 34, 1998, 45-106

22. Lilley, J.S., "Reduced-length scarfed-nozzles for thrust vector adjustment", AIAA Journal of Propulsion and Power, Vol. 9, $1993,233-239$.

23. New, T.H., “An experimental study on jets issuing from elliptic inclined nozzles”, Exp. Fluids, Vol. 46, 2009, pp. 1139-1157.

24. New, T.H., Tsovolos, D., "On the vortical structures and behaviour of inclined elliptic jets”, European Journal of Mechanics B/Fluids, Vol.30, 2011, 437-450.

25. Samimy, M., Kim, J-H, Clancy, P. S., Martens, S. "Passive control of supersonic rectangular jets via nozzle trailing-edge modifications", AIAA Journal, Vol. 36, 1998, 1230-1239.

26. Kim, J-H., Samimy, M., "Mixing enhancement via nozzle trailing edge modifications in a high speed rectangular jet", Physics of Fluids, vol. 11, 1999, 2731-2742.

27. Georgiadis, N. J., DeBonis, J. R., "Navier-Stokes analysis methods for turbulent jet flows with application to aircraft exhaust nozzles", Progress in Aerospace Sciences, Vol. 42, 2006, 377-418.

28. Thies, A. T., Tam, C. K. W., "Computation of turbulent axisymmetric and non-axisymmetric jet flows using the k- $\varepsilon$ Model”, AIAA Journal, Vol. 34, 1996, 309-316. 
29. Wang, P.C., McGuirk, J. J., "Large Eddy Simulation of supersonic jet plumes from rectangular con-di nozzles”, International Journal of Heat and Fluid Flow, Vol. 43, 2013, 62-73.

30. Crumpton, P. I., Moinier, P., Giles, M. G., “An unstructured algorithm for high Reynolds number flows on highly stretched grids" $10^{\text {th }}$ International Conference on Numerical Methods for Laminar and Turbulent flow, 1997.

31. Hills, N., "Achieving high parallel performance for an unstructured unsteady turbomachinery code", The Aeronautical Journal, 2007, Vol. 111, 185-193.

32. Spalart, P. R., Almaras, S. A., “A one-equation turbulence model for aerodynamic flows, AIAA Paper 92-0439, 1992.

33. Babu, P. C., Manesh, K., "Upstream entrainment in numerical simulations of spatially evolving round jets", Physics of Fluids, Vol. 16, 2004, 3699-3705. 